\title{
Review of ionospheric irregularities and ionospheric electrodynamic coupling in the middle latitude region
}

\author{
Yi Liu' ${ }^{1}$, Chen Zhou ${ }^{1}{ }^{*}$, Tong Xu' ${ }^{2}$, Qiong Tang ${ }^{1}$, ZhongXin Deng ${ }^{2}$, GuanYi Chen ${ }^{1}$, and ZhuangKai Wang' \\ 'Department of Space Physics, School of Electronic Information, Wuhan University, Wuhan 430072, China; \\ ${ }^{2}$ National Key Laboratory of Electromagnetic Environment, China Research Institute of Radiowave Propagation, Qingdao 266107, China \\ Key Points: \\ - We review and discuss current research related to ionospheric irregularities in the middle latitude region. \\ - The generation of mid-latitude ionospheric irregularities depends on the effects of electric fields and neutral winds. \\ - We also discuss the effect of electrodynamic coupling processes on the evolution of ionospheric irregularities in the mid-latitude \\ region.
}

Citation: Liu, Y., Zhou, C., Xu, T., Tang, Q., Deng, Z. X., Chen, G. Y., and Wang, Z. K. (2021). Review of ionospheric irregularities and ionospheric electrodynamic coupling in the middle latitude region. Earth Planet. Phys., 5(5), 462-482.

http://doi.org/10.26464/epp2021025

\begin{abstract}
This paper briefly reviews ionospheric irregularities that occur in the $E$ and $F$ regions at mid-latitudes. Sporadic $E\left(E_{s}\right)$ is a common ionospheric irregularity phenomenon that is first noticed in the E layer. $E_{S}$ mainly appears during daytime in summer hemispheres, and is formed primarily from neutral wind shear in the mesosphere and lower thermosphere (MLT) region. Field-aligned irregularity (FAI) in the E region is also observed by Very High Frequency (VHF) radar in mid-latitude regions. FAI frequently occurs after sunset in summer hemispheres, and spectrum features of $E$ region FAl echoes suggest that type- 2 irregularity is dominant in the nighttime ionosphere. A close relationship between $E_{S}$ and $E$ region $F A l$ implies that $E_{S}$ may be a possible source of $E$ region $F A I$ in the nighttime ionosphere. Strong neutral wind shear, steep $E_{S}$ plasma density gradient, and a polarized electric field are the significant factors affecting the formation of E region FAI. At mid-latitudes, joint observational experiments including ionosonde, VHF radar, Global Positioning System (GPS) stations, and all-sky optical images have revealed strong connections across different scales of ionospheric irregularities in the nighttime $\mathrm{F}$ region, such as spread F (SF), medium-scale traveling ionospheric disturbances (MSTID), and F region FAI. Observations suggest that different scales of ionospheric irregularities are generally attributed to the Perkins instability and subsequently excited gradient drift instability. Nighttime MSTID can further evolve into small-scale structures through a nonlinear cascade process when a steep plasma density gradient exists at the bottom of the $\mathrm{F}$ region. In addition, the effect of ionospheric electrodynamic coupling processes, including ionospheric E-F coupling and inter-hemispheric coupling on the generation of ionospheric irregularities, becomes more prominent due to the significant dip angle and equipotentiality of magnetic field lines in the mid-latitude ionosphere. Polarized electric fields can map to different ionospheric regions and excite plasma instabilities which form ionospheric irregularities. Nevertheless, the mapping efficiency of a polarized electric field depends on the ionospheric background and spatial scale of the field.
\end{abstract}

Keywords: ionospheric irregularity; plasma instability; neutral wind; polarized electric field; ionospheric electrodynamic coupling

\section{Introduction}

The ionosphere is the region of the upper atmosphere that is partially ionized by high-energy solar radiation from about $60 \mathrm{~km}$ to thousands of kilometers above the Earth's surface; it is an important transition region connecting the lower atmosphere and magnetosphere in the near-earth space environment. As a result of photoionization and transport processes, the ionosphere is divided into the $D$ region (60-90 km), E region (90-150 km), and $F$ region (150-1000 km). During the day, the $F$ region is further split

Correspondence to: C. Zhou, chenzhou@whu.edu.cn

Received 31 JAN 2021; Accepted 15 APR 2021.

Accepted article online 19 MAY 2021.

(C) 2021 by Earth and Planetary Physics. into the $F_{1}$ region $(150-220 \mathrm{~km})$ and $F_{2}$ region $(220-1000 \mathrm{~km})$.

The spatial and temporal distribution of charged particles in the ionosphere is influenced by many factors, including the electrodynamics of the Earth's magnetic field and other processes driven by neutral wind (Kelley, 2009). In addition, ionospheric charged particles can modulate the propagation of radio waves, significantly impacting communications, navigation, and radar systems (Ratcliffe, 1972).

Many studies have revealed large numbers of ionospheric irregularities with a spatial scale from meters to thousands of kilometers, manifesting as sporadic $E\left(E_{S}\right)$ and spread $F(S F)$ in ionograms (Bowman, 1990; Zhou C et al., 2017), field-aligned irregularities (FAls), plasma bubbles in radar maps (Kelley et al., 1981; 
Yamamoto et al., 1991; Zhou C et al., 2018a; Liu Y et al., 2019), traveling ionospheric disturbances (TIDs) in optical images, and total electron content (TEC) perturbation maps (Ding $F$ et al., 2011; Huang FQ et al., 2016). When radio waves transit an ionospheric irregularity, radio signals may undergo severe signal loss and phase cycle slips known as ionospheric scintillations (Basu et al., 1988), which can affect modern communication and navigation system performance.

The formation of irregularities is generally attributed to ionospheric instability mechanisms, including: wind shear theory for $E_{S}$ (Mathews, 1998); two-stream instability (TSI) and gradient-drift instability (GDI) for $\mathrm{E}$ region FAls at the equator and low latitudes (Farley, 1963; Simon, 1963); atmospheric gravity waves, GDI, Kelvin-Helmholtz instability (KHI), and $\mathrm{E}_{s}$-layer instability for $\mathrm{E}$ region FAls at mid-latitudes (Woodman, 1991; Larsen, 2000; Maruyama et al., 2000; Cosgrove and Tsunoda, 2002a); RayleighTaylor (R-T) instability for plasma bubbles and equatorial SF (Dungey, 1956; Basu and Kelley, 1979; Fejer and Kelley, 1980; Abdu, 2001); and the breaking of atmospheric gravity waves and Perkins instability for SF and medium-scale TIDs (MSTIDs) at mid-latitudes (Perkins, 1973; Bowman, 1990, 1991; Liu Y et al., 2019). In all of the above instability mechanisms, electric fields and neutral winds play dominant roles in the generation of ionospheric irregularities.

Unlike the equatorial and polar regions, the significant dip angle and equipotentiality of magnetic field lines in the mid-latitude regions cause an apparent electrodynamic coupling relationship between ionospheric irregularities in the $E$ and $F$ regions. The importance of electrodynamic coupled processes in generating ionospheric irregularities has been extensively investigated using observations and numerical simulations, suggesting that ionospheric instabilities could be easily excited by coupled processes along magnetic field lines (Bowman, 1960; Haldoupis et al., 2003; Kelley et al., 2003; Cosgrove and Tsunoda, 2004; Yokoyama et al., 2009; Zhou C et al., 2018b; Liu Y et al., 2019, 2020).

In this paper, we focus on the morphological characteristics and generation mechanisms of ionospheric irregularities in the midlatitude region, especially ionospheric electrodynamic coupling processes. Recent observational studies of ionospheric irregularities in this region using ionosondes, Very High Frequency (VHF) radar, airglow imagers, the Global Navigation Satellite System (GNSS) network, the Constellation Observing System for Meteorology, lonosphere, and Climate (COSMIC) radio occultation (RO) measurements, and low Earth orbit (LEO) satellites are presented. E region irregularity, $\mathrm{F}$ region irregularity, and ionospheric electrodynamic coupling phenomena are reviewed in Sections 2, 3, and 4 , respectively.

\section{E Region Irregularity}

$E_{S}$ and $E$ region FAls are two significant irregular phenomena in the mid-latitude region whose morphological features have been widely studied for over 70 years, with plasma electrodynamic processes generally considered to be the major influences (Larsen, 2000; Cosgrove and Tsunoda, 2002b). A strong linkage between $E_{S}$ and $\mathrm{E}$ region $\mathrm{FAl}$ is also revealed by several studies (Ogawa, 2002; Zhou $C$ et al., 2018a, b). Next, we review the recent research on $E$ region irregularities.

\subsection{Sporadic E}

$E_{S}$, an enhanced metallic ionization layer, is frequently observed in the $E$ region from $90-140 \mathrm{~km}$. As far back as the 1950s, researchers studied the temporal and spatial distribution of $E_{S}$ using ionosonde. Previous statistical studies have shown that $E_{S}$ occurrence has a clear local time and seasonal dependence (Smith, 1957; Arras et al., 2008; Chu YH et al., 2014). Es develops in the early morning at $\sim 6$ local time (LT), reaching a maximum intensity at around $14 \mathrm{LT}$ and $20 \mathrm{LT}$ for summer hemispheres in the mid-latitude region. The local time and seasonal variations of $E_{S}$ occurrence rate observed by four ionosondes located at Mohe $\left(122.37^{\circ} \mathrm{E}, 53.50^{\circ} \mathrm{N}\right)$, Beijing $\left(116.25^{\circ} \mathrm{E}, 40.25^{\circ} \mathrm{N}\right)$, Wuhan $\left(114.61^{\circ} \mathrm{E}, 30.53^{\circ} \mathrm{N}\right)$, and Hainan $\left(109.13^{\circ} \mathrm{E}, 19.52^{\circ} \mathrm{N}\right)$, China, are shown in Figure 1 (Zhou $\mathrm{C}$ et al., 2017). The occurrence rate of $E_{S}$ is calculated as the ratio of the number of $E_{S}$ observations to the total number of ionograms in each bin in Figure 1. Intense $E_{S}$ layer was more prevalent around local noon and after sunset during summer at all stations.

Neutral wind shear theory has been proposed to explain the formation of $E_{S}$ in the mid-latitude region (Whitehead, 1960). Under the combined action of geomagnetic fields and zonal wind, metallic ions are pushed upward by eastward winds at lower altitudes and downward by westward winds at higher altitudes, converging near the shear node to form the thin $E_{S}$ layer. The relationship between $E_{S}$ occurrence rate and neutral wind shear (as shown in Figure 2) was recently described by Liu $Y$ et al. (2018). A more frequent occurrence of $E_{S}$ observed by measuring $\mathrm{RO}$ at mid-latitudes is also presented in Figure 2, consistent with previous studies (Arras et al., 2008; Chu YH et al., 2014). The global distribution of wind shear measured by TIMED/TIDI and simulated by Horizontal Wind Model 14 (HWM14) have similar seasonal and latitude characteristics with the rate of $\mathrm{E}_{\mathrm{S}}$ occurrence (Figure 2). Furthermore, the annual variation of meteor deposition may explain the maximum occurrence of $E_{S}$ during summer (Haldoupis et al., 2007).

Recent statistical studies also find that $E_{S}$ occurrence rate may be affected by geomagnetic activity, although the relationship is complex and varies with local time and latitude (Zhang YB et al., 2015; Zhou $C$ et al., 2017). Positive, negative, and no correlation between $\mathrm{E}_{\mathrm{S}}$ occurrence and geomagnetic activity have all been reported (Maksyutin and Sherstyukov, 2005; Pietrella and Bianchi, 2009). The variation in $E_{S}$ occurrence with $K p$ index measured by four ionosondes at mid-latitudes is presented in Figure 3. Under moderate $(3 \leq K p<6)$ and active geomagnetic conditions $(6 \leq$ $K p<9)$, Es occurs more frequently than under quiet geomagnetic conditions $(0 \leq K p<3)$. The prompt penetration electric field (PPEF), zonal electric field disturbances in the MLT region, and changes in lower thermospheric composition during geomagnetic storms may be the mechanisms for the effect of geomagnetic activity on $E_{S}$ occurrence (Abdu et al., 2013, 2014; Zhang YB et al., 2015).

A close relationship between $E_{S}$ and atmospheric waves has been revealed by many studies (MacDougall, 1974; Wilkinson et al., 1992; Haldoupis et al., 2006; Haldoupis, 2012; Zhou C et al., 2017). 24-hour, 12-hour, and 8-hour tidal period components are frequently observed in critical frequency of $\mathrm{E}_{\mathrm{S}}\left(f_{\mathrm{o}} \mathrm{E}_{\mathrm{S}}\right)$ time series (Haldoupis et al., 2004). Planetary waves could also affect the forma- 

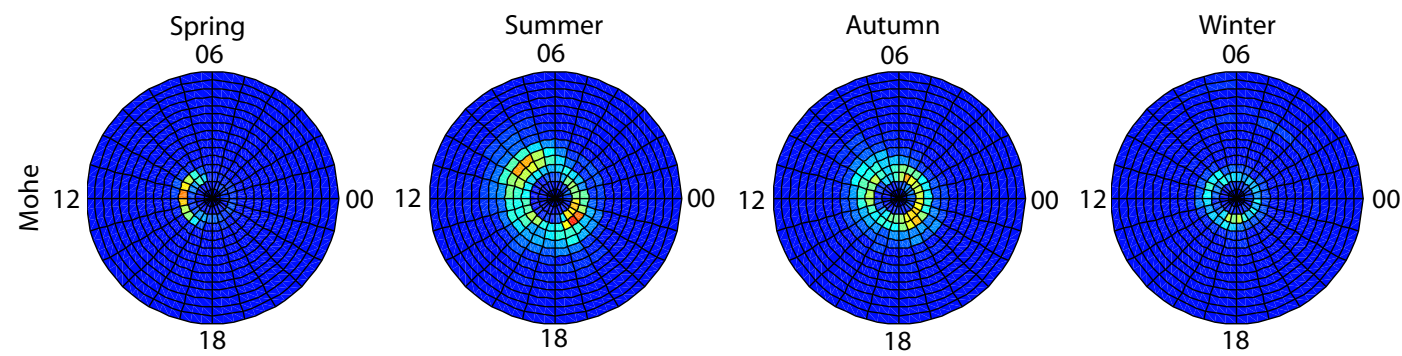

00

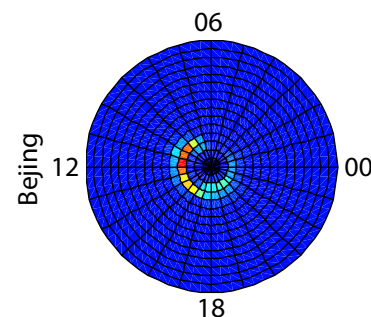

06
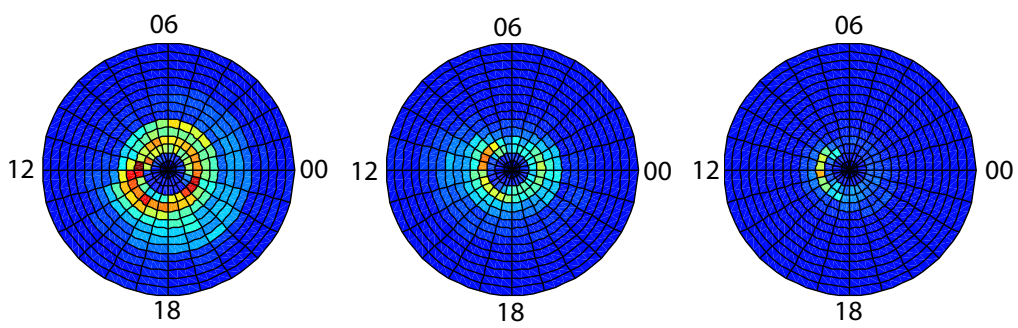

70

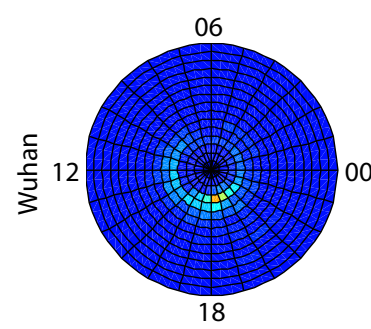

06
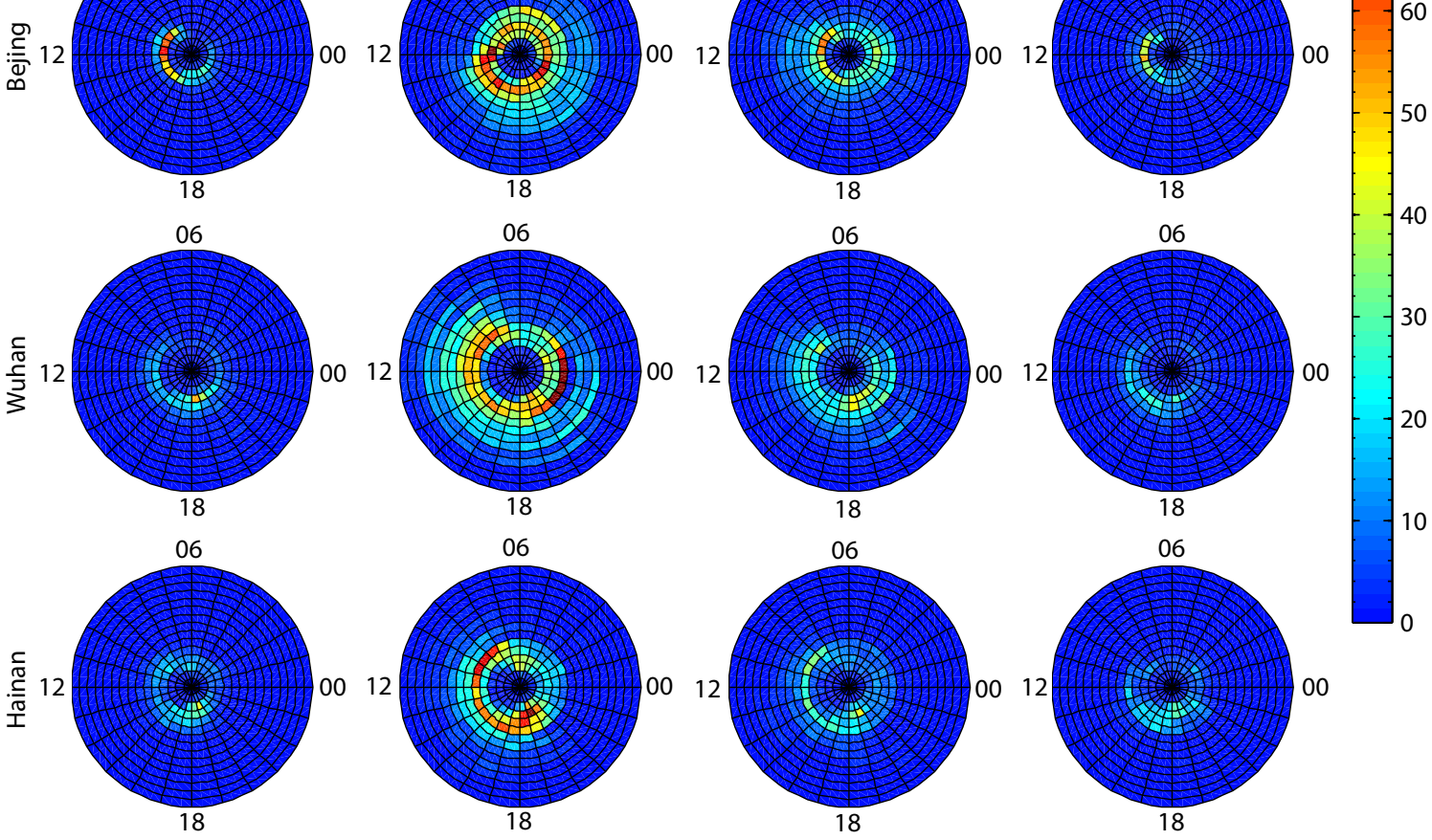

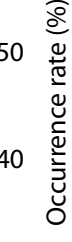

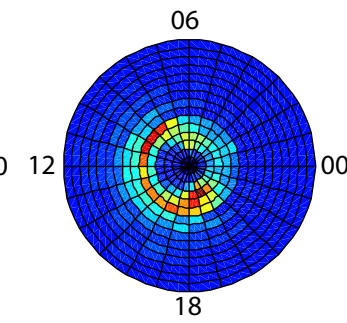

Figure 1. $E_{S}$ occurrence rate (\%) at four ionosondes located at Mohe $\left(122.37^{\circ} \mathrm{E}, 53.50^{\circ} \mathrm{N}\right)$, Beijing $\left(116.25^{\circ} \mathrm{E}, 40.25^{\circ} \mathrm{N}\right), \mathrm{Wuhan}\left(114.61^{\circ} \mathrm{E}, 30.53^{\circ} \mathrm{N}\right)$, and Hainan $\left(109.13^{\circ} \mathrm{E}, 19.52^{\circ} \mathrm{N}\right)$ during $2011-2015$. Distributions are binned function of local time (anti-clockwise direction) and critical frequency of $\mathrm{E}_{\mathrm{S}}\left(f_{\mathrm{o}} \mathrm{E}_{\mathrm{S}}\right)$ from $0 \mathrm{MHz}$ to $15 \mathrm{MHz}$ in steps of $1 \mathrm{MHz}$ (radial direction), which sorted into spring (March, April, and May), summer (June, July, and August), autumn (September, October, and November), and winter (December, January, and February) (after Zhou C et al., 2017).

tion of $E_{S}$ by modulating atmospheric tidal wave amplitude (Pancheva et al., 2003). A 14.5-day semimonthly lunar period component is found to cause the $E_{s}$ layer variations during Sudden Stratospheric Warming (SSW) events as shown in Figure 4. During SSW events, the reversal of zonal winds as well as thermal temperature variations in the stratosphere and mesosphere could affect the propagation of lunar tides (Lindzen and Hong, 1974; Stening et al., 1997; Pedatella et al., 2012). The enhancement of the 14.5day semimonthly lunar period component in the MLT region, eventually produces variations in the $E_{S}$ layer, shown in Figure 5 (Tang Q et al., 2020).

\subsection{E Region Field-Aligned Irregularity}

E region FAls have been observed using VHF radar since the 1960s. The first observation of $E$ region FAls was by Cohen and Bowles (1967) using Jicamarca VHF radar in the equatorial region. Radar spectral studies have found that $E$ region FAls could be divided into two types. Type- 1 irregularities with a narrow spec- trum could be excited by TSI, while type-2 irregularities with a broader Doppler width are associated with GDI. In the mid-latitude region, Yamamoto et al. (1991) first reported that E region FAI echoes could be classified into two types, continuous type echoes and quasi-periodic (QP) type echoes, according to different radar features. An example of $E$ region FAls observed using Wuhan VHF radar $\left(30.54^{\circ} \mathrm{N}, 114.37^{\circ} \mathrm{E}\right)$ is shown in Figure 6. The radar data indicate that continuous-type echoes mainly occurred between 90-110 km after sunrise, whereas QP-type echoes appeared above $100 \mathrm{~km}$ within a 10-15 min post-sunset period. Recent observations provided by the second Sporadic E Experiment over Kyushu (SEEK-2) found a close connection between $E$ region FAls and $E_{S}$ (Larsen et al., 2005). This correlation was further supported by numerical simulations (Maruyama et al., 2006; Li GZ et al., 2013, 2014), indicating that $E$ region $F A l$ echoes occur more often with a greater $E_{S}$ density gradient (Figure 7).

The $\mathrm{E}$ region FAls at mid-latitudes cannot be directly driven by TSI or GDI. According to the TSI mechanism, the external electric field 

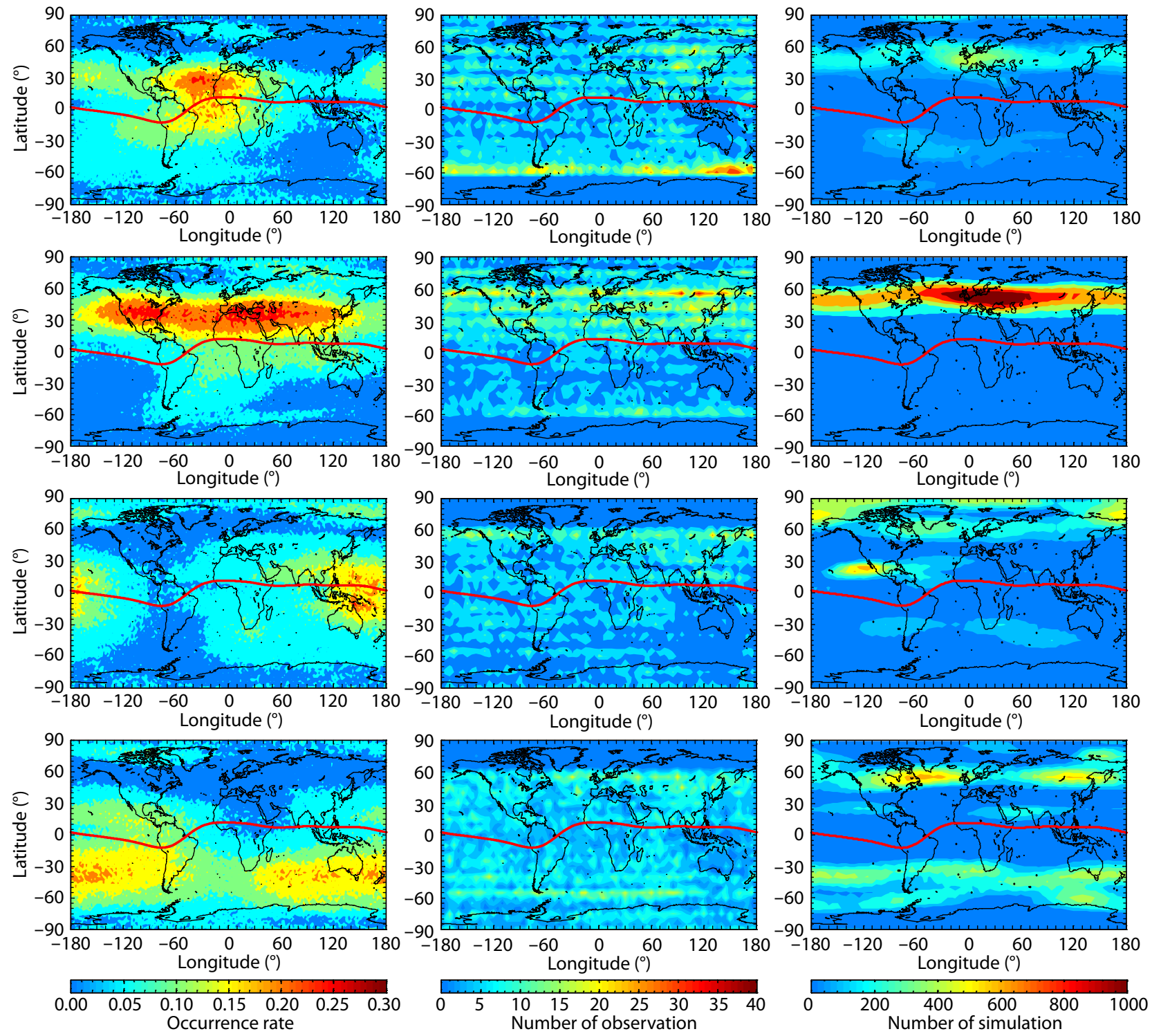

Figure 2. The seasonal distribution of global $E_{S}$ occurrence rate observed by COSMIC, GRACE and CHAMP (first column) and wind shear occurrence measured by TIMED/TIDI (second column) and simulated by HWM 14 (third column). Distributions are binned within a $5^{\circ} \times 5^{\circ}$ resolution during 2002-2016 (after Liu Y et al., 2018).

triggering TSI should be greater than $10 \mathrm{mV} / \mathrm{m}$, which is difficult to reach at mid-latitudes. The type-1 irregularity echoes were first reported by Schlegel and Haldoupis (1994) using Sporadic E Scatter (SESCAT) radar. Haldoupis et al. (1996) proposed that when there is a steep horizontal ionospheric conductivity gradient of $E_{S}$ along the zonal direction at night, zonal polarized electric field could be sufficiently excited to meet the threshold for triggering TSI. However, the spatial structure of the $E_{S}$ layer rarely meets the conditions triggering TSI at mid-latitudes, which may explain why type-1 $\mathrm{E}$ region irregularity echoes are infrequently observed at in this region. Recent observations of $\mathrm{E}$ region $\mathrm{FAl}$ echoes at Wuhan show that type-2 irregularities occur more often during local night at mid-latitudes (Figure 8). Maruyama et al. (2000) described the formation of oblique stripes in E region FAl echoes is associated with GDI. The polarized electric field excited in the blocky $E_{S}$ structure could map to the higher $E$ layer and generate the sheet plasma density structure along magnetic field lines, which triggers GDI on the side where the polarized electric field and plasma density gradient are parallel and eventually results in the generation of QP echoes in radar maps. Haldoupis and Schlegel (1996) and Yamamoto et al. (1991) have also attributed the generation of continuous-type echoes in the $\mathrm{E}$ region at mid-latitudes to GDI according to spectral characteristics. However, it should be pointed out that the electron density gradient of $\mathrm{E}_{\mathrm{S}}$ is not perpendicular to the magnetic field, which is inclined at mid-latitudes. According to the GDI mechanism, when $E_{S}$ is driven by an electric field or neutral wind, instability will be triggered on one side of $E_{S}$, while the other side will remain stable. Recent studies proposed that instabilities on one side of $E_{S}$ will be inhibited by the mapping of a polarized electric field excited on the other side along magnetic field lines (Woodman et al., 1991).

E region QP echoes at mid-latitudes were first thought to be asso- 

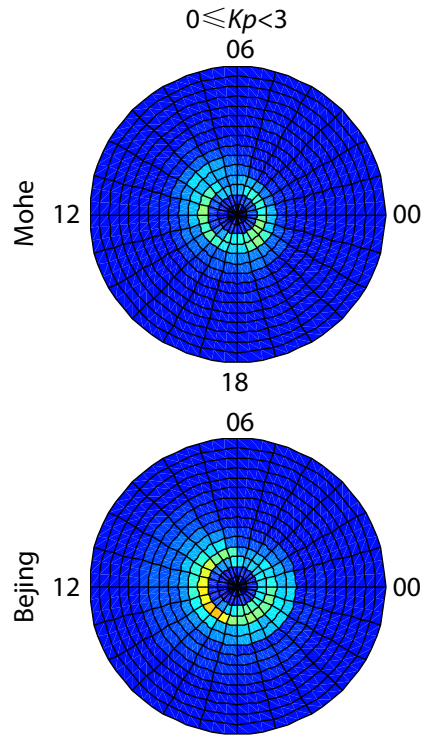

18
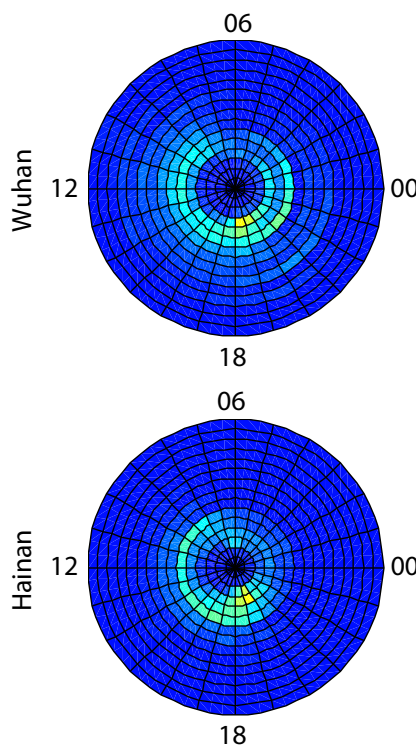
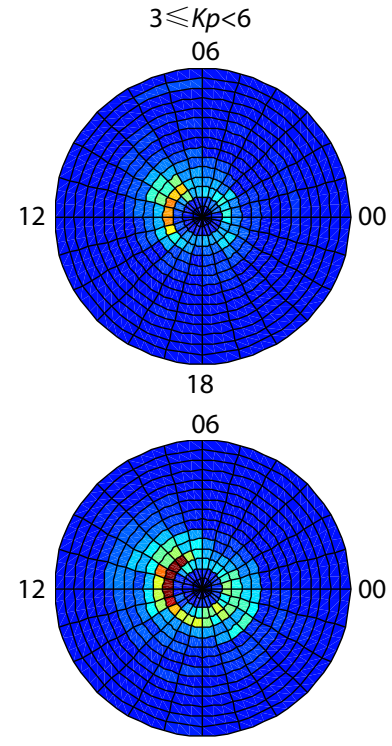

18

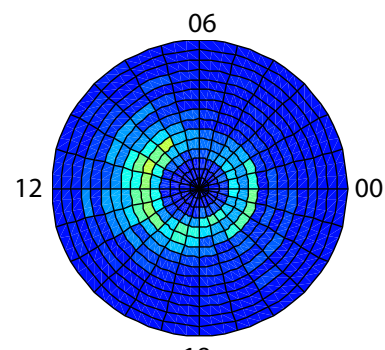

18

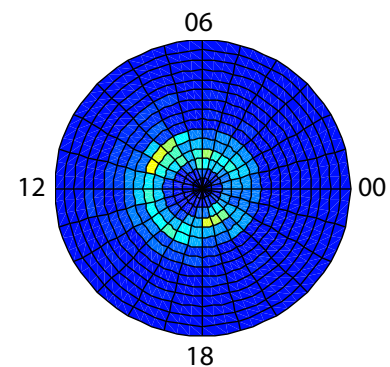

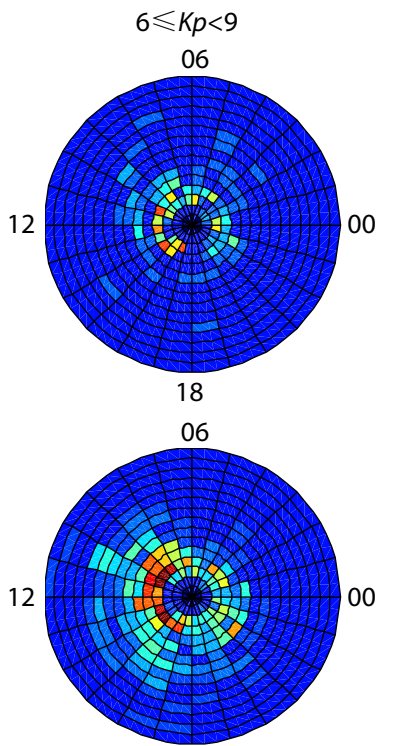

18

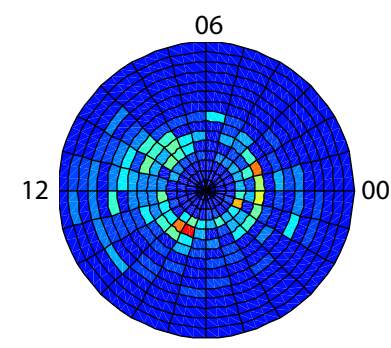

18

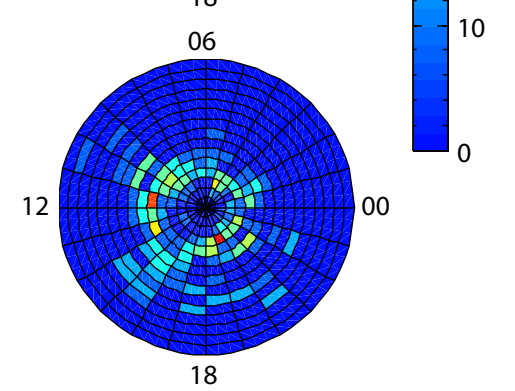

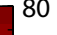

70

60

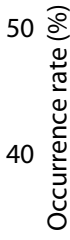

30

20

Figure 3. $\mathrm{E}_{\mathrm{S}}$ occurrence rate (\%) at four ionosondes located at Mohe $\left(122.37^{\circ} \mathrm{E}, 53.50^{\circ} \mathrm{N}\right), \mathrm{Beijing}\left(116.25^{\circ} \mathrm{E}, 40.25^{\circ} \mathrm{N}\right), \mathrm{Wuhan}\left(114.61^{\circ} \mathrm{E}, 30.53^{\circ} \mathrm{N}\right)$, and Hainan $\left(109.13^{\circ} \mathrm{E}, 19.52^{\circ} \mathrm{N}\right)$ during $2011-2015$. Distributions are binned functions of local time and $f_{\mathrm{O}} \mathrm{E}_{\mathrm{S}}$, which is categorized by $K p$ index (after Zhou C et al., 2017).

ciated with atmospheric gravity waves (Woodman et al., 1991 and Yamamoto et al., 1991, 1992). Gravity waves close to the BruntVäisälä frequency could excite QP echoes with a period of several minutes by modulating $E_{s}$. However, small-scale irregular structures ( $3 \mathrm{~m}$ characteristic scale) cannot be generated by simple gravity wave modulation. Woodman et al. (1991) suggested that the horizontal structure of $E_{S}$ is gradually distorted into a jagged structure through gravity wave modulation, which results in the formation of an electron density gradient perpendicular to the magnetic field. Then GDI could be excited and generate a smallscale irregular structure; subsequent observations have confirmed this theory (Yamamoto et al., 1994). However, gravity wave theory cannot explain larger Doppler velocity in radar maps. In order to solve this problem, Tsunoda et al. (1994) further improved and developed the gravity wave mechanism, and proposed that the polarization process will be excited in the gravity wave modu- lation process. The larger polarized electric field will drive the increased Doppler velocity in QP echoes.

According to gravity wave theory, there are very high requirements for gravity wave amplitude and wave number matching conditions, but there is not much observational evidence to show that suitable gravity wave structures could be frequently observed in the $E$ layer at mid-latitudes. SEEK and SEEK2 experiments observed that the neutral wind also plays a key role in the excitation process of instability (Kagan and Kelley, 1998). Zonal wind shear can not only form $E_{S}$, but triggers GDI on both sides of $E_{S}$ eventually leading to the excitation of instability and the generation of small-scale irregular structures. Larsen et al. (1998) and Larsen (2000) reported that the zonal wind shear strength at the $\mathrm{E}$ layer can be greater than $40 \mathrm{~m} \cdot \mathrm{s}^{-1} \cdot \mathrm{km}^{-1}$, which is sufficient to induce Kelvin-Helmholtz instability $(\mathrm{KHI})$ in the neutral atmosphere. 


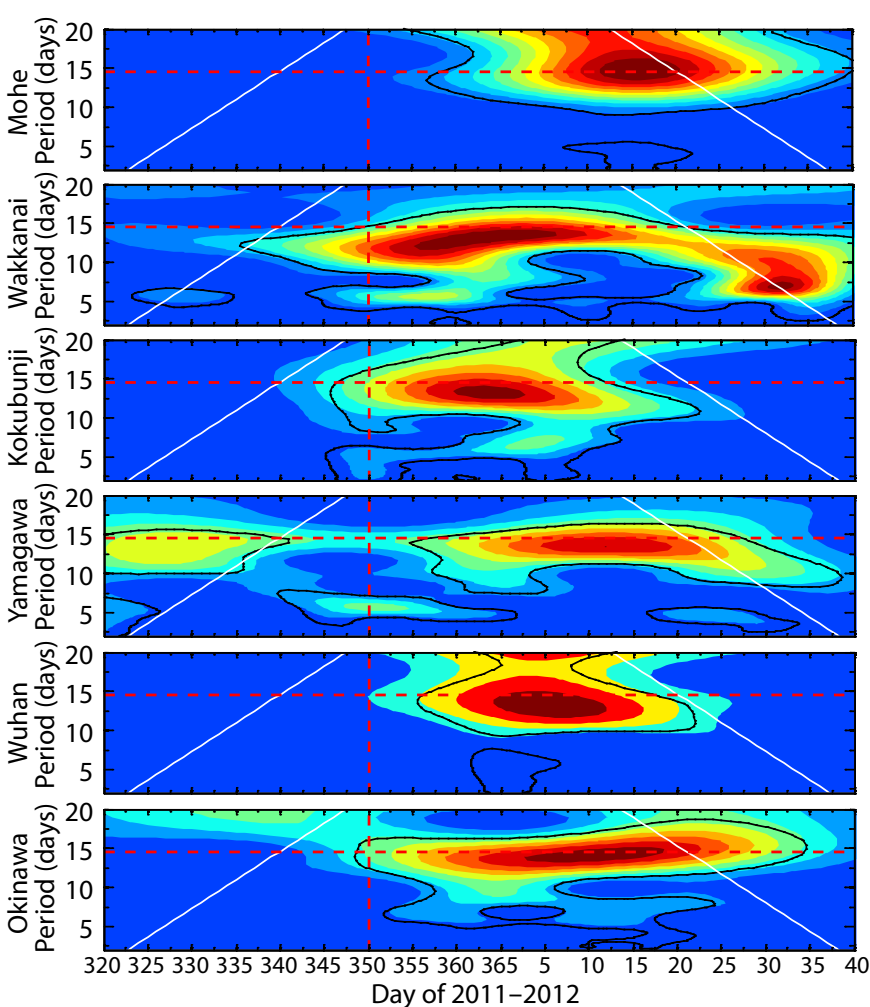

(a)
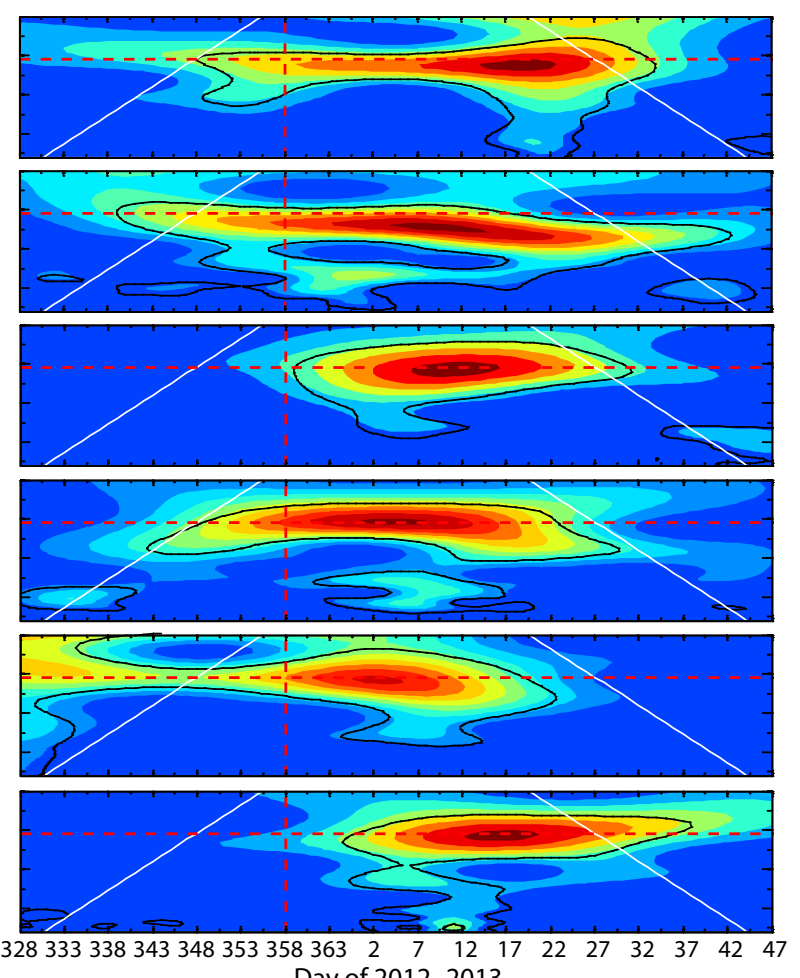

Day of 2012-2013

(b)

Figure 4. The time variations of $f_{\mathrm{o}} \mathrm{E}_{S}$ spectrum observed by six ionosondes located at Mohe $\left(122.37^{\circ} \mathrm{E}, 53.50^{\circ} \mathrm{N}\right), \mathrm{Wakkanai}\left(141.75^{\circ} \mathrm{E}, 45.16^{\circ} \mathrm{N}\right)$, Kokubunji $\left(139.49^{\circ} \mathrm{E}, 35.71^{\circ} \mathrm{N}\right)$, Yamagawa $\left(130.62^{\circ} \mathrm{E}, 31.20^{\circ} \mathrm{N}\right)$, Wuhan $\left(114.61^{\circ} \mathrm{E}, 30.53^{\circ} \mathrm{N}\right)$, and Okinawa $\left(128.15^{\circ} \mathrm{E}, 26.68^{\circ} \mathrm{N}\right)$ during two SSW events. The warming onset is indicated by the red vertical dashed line, while the red horizontal dashed line denotes the 14.5-day period (after Tang Q et al., 2020).

Driven by $\mathrm{KHI}, \mathrm{E}_{\mathrm{S}}$ structure is destabilized by collision between plasma and neutral particles, and then evolves into the K-H structure, resulting in QP echoes in radar maps. Correlative studies have been performed by Sripathi et al. (2003) and Patra et al. (2009). A 2-D numerical model of the evolution of $E_{S}$ in $\mathrm{KHI}$ modulation is shown in Figure 9 (Bernhardt, 2002). However, KHI theory cannot explain the extended nighttime E region QP echoes (2-8 hour) at mid-latitudes (Venkateswara Rao et al., 2008).

Recent models have indicated that neutral wind shear could excite a relatively large polarized electric field in $E_{S}$ (Cosgrove and Tsunoda, 2001, 2002a). A new instability mechanism for generating $E$ region irregularity, called $\mathrm{E}_{\mathrm{S}}$-layer instability, is proposed by Cosgrove and Tsunoda (2002b). Under the action of zonal wind shear, the nighttime $E_{S}$ layer at mid-latitudes becomes unstable due to the modulation of the integral Hall conductivity along the magnetic field and height direction, resulting in a horizontal plane wave-like distribution. Earlier model calculations of $E_{S}$-layer instability growth rate predicted that $\mathrm{E}$ region irregularities align in a northwest-southeast (NW-SE) direction in the northern hemisphere, consistent with observations of the structure of $E$ region irregularities. Cosgrove and Tsunoda (2003) first presented the 2-D evolution of $E_{S}$ modulated by $E_{S}$-layer instability, and reported that the spatial scale of irregularities ranges from $100 \mathrm{~m}$ to $100 \mathrm{~km}$ (Figure 10). In addition, a polarized electric field larger than $10 \mathrm{mV} / \mathrm{m}$ could be excited in a Hall current-driven polarization process (Tsunoda et al., 2004).

\section{F Region Irregularity}

Plasma instability phenomena occurring in the ionospheric $\mathrm{F}$ region at mid-latitudes are usually grouped under the generic name SF based on earlier observations using ionosondes. Recent research found that some of the more violent disturbances that include TID and small-scale structure were also observed in the ionospheric $\mathrm{F}$ region. A close relationship among different scales of ionospheric irregularity structures was revealed through joint observations (Saito et al., 2002; Otsuka et al., 2009; Liu Y et al., 2019). Recent research on $F$ region irregularities in the mid-latitudes is reviewed below.

\subsection{Observations}

A general nighttime ionospheric irregularity phenomenon, an extension of $\mathrm{F}$ layer trace with height and frequency in ionograms, has been identified as SF since it was first observed by Booker and Wells (1938). SF traces in ionograms are generally divided into four types: frequency SF (FSF), range spread $F$ (RSF), mix spread $F$ (MSF), and strong spread F (SSF) (Shi JK et al., 2011). Long-term observations have suggested that SF varies by latitude, longitude, local time, season, solar activity, and geomagnetic activity (Abdu et al., 1981, 1985; Dabas et al., 2007; Li GZ et al., 2010; Wang GJ et al., 2010; Wang N, 2018).

MSTID is a typical ionospheric wave-like electron density perturbation structure in the $\mathrm{F}$ layer at mid-latitudes, with a horizontal 

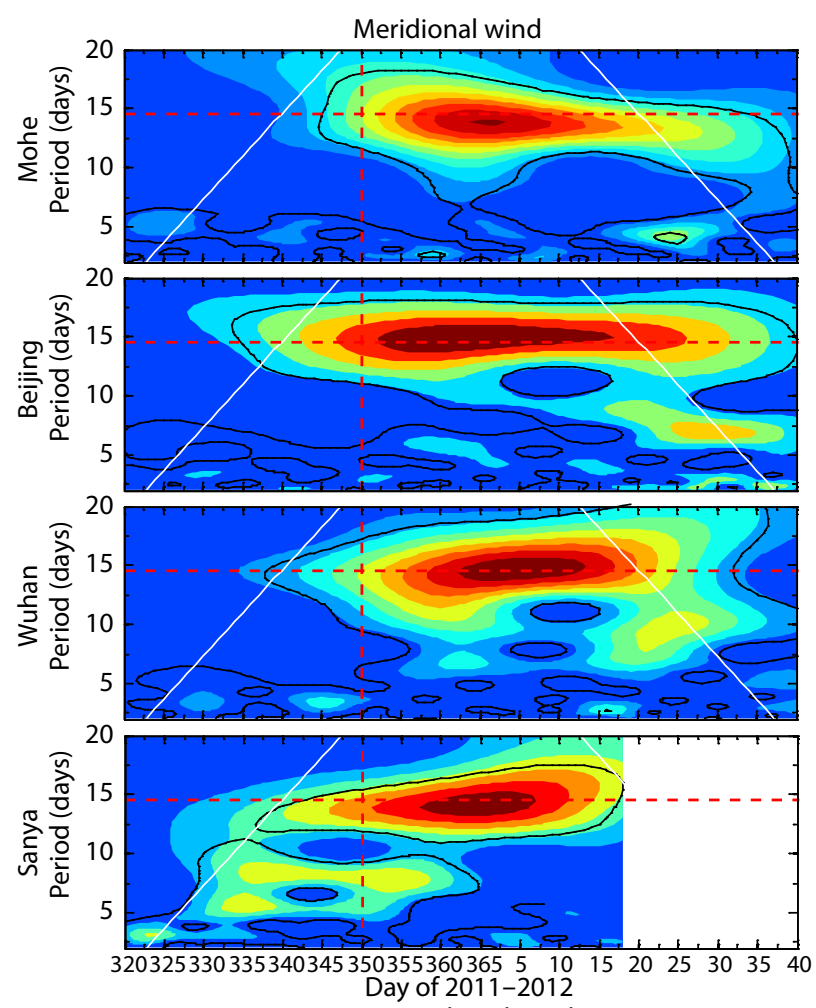

Day of 2011-2012
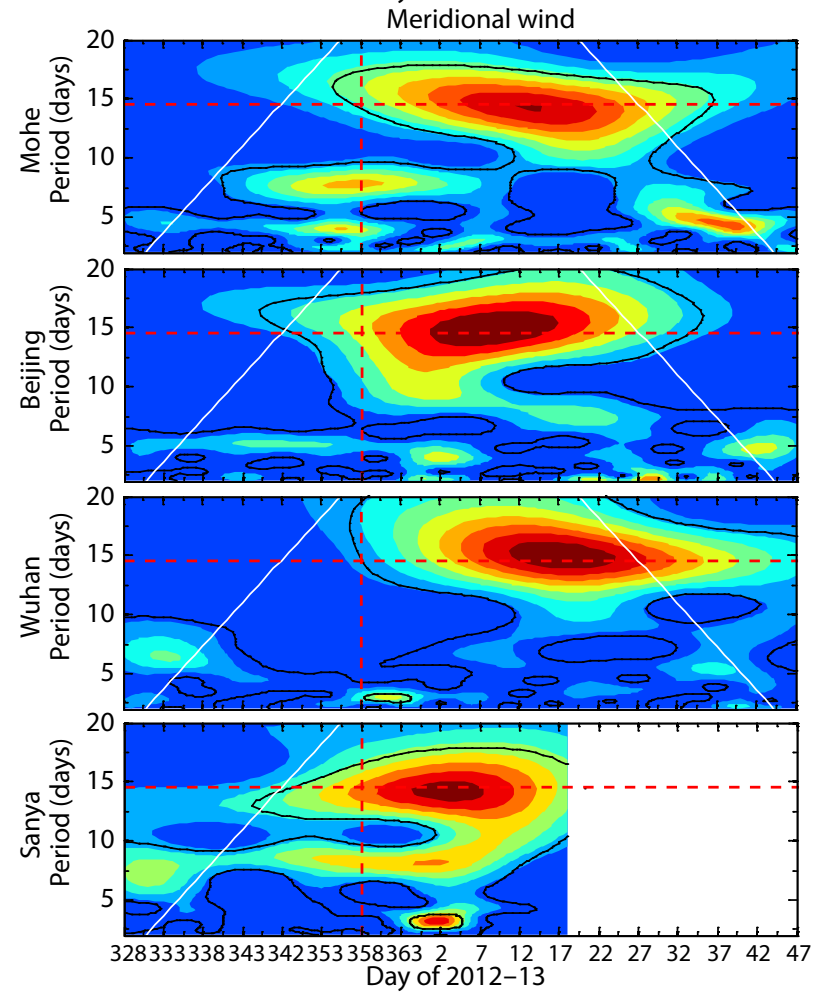
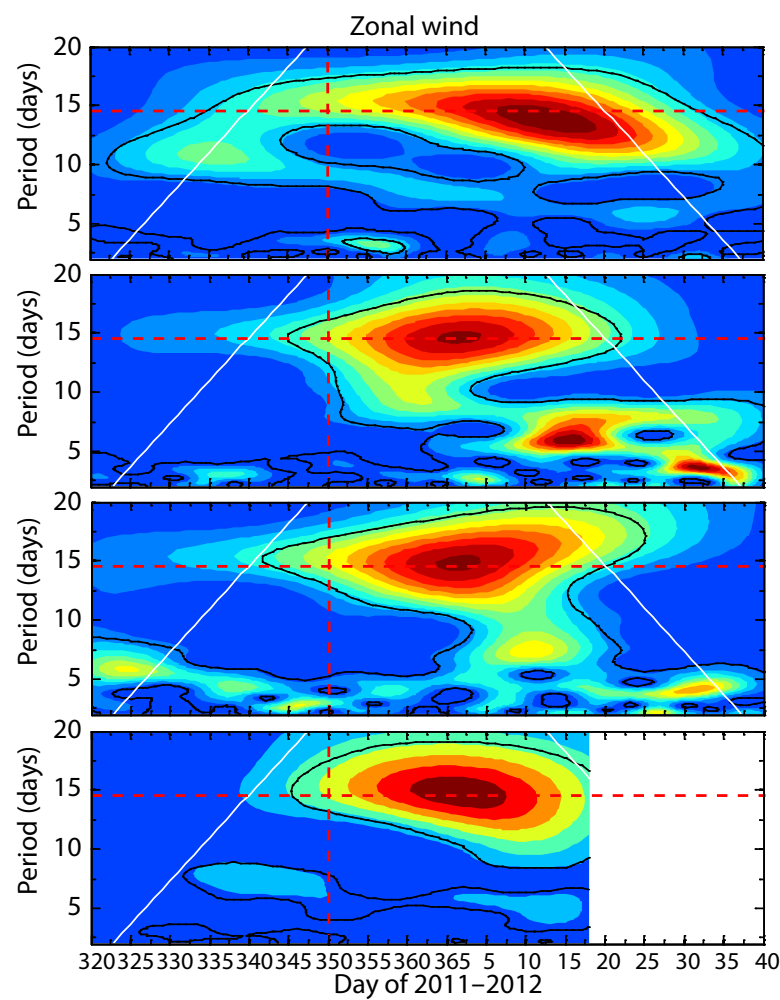

Zonal wind
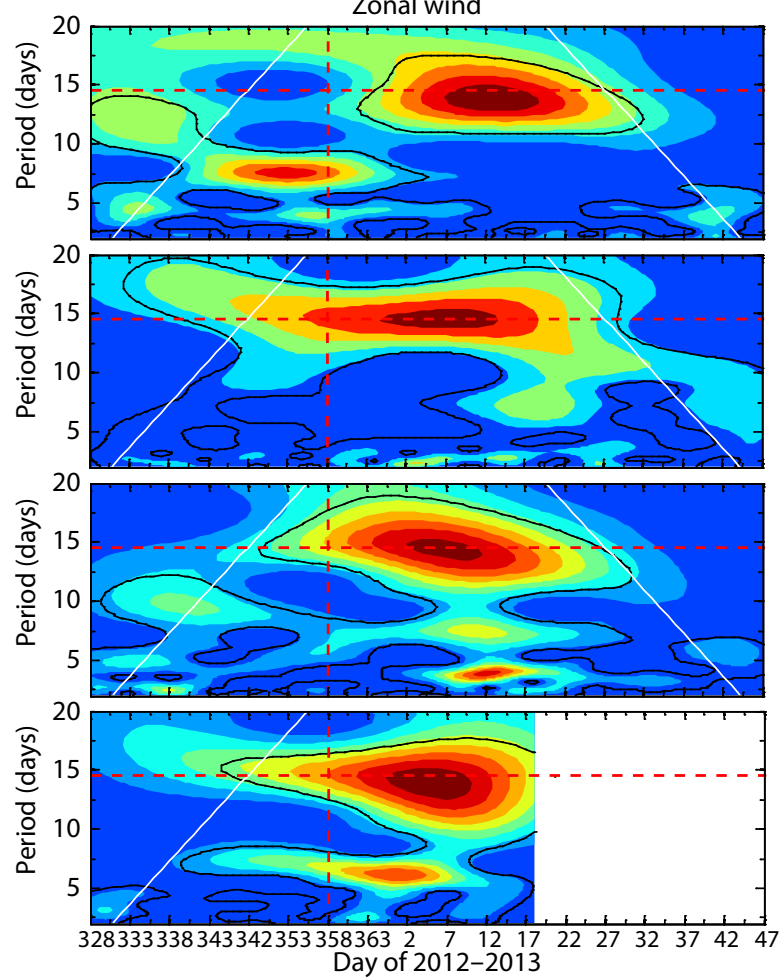

Figure 5. Power spectra of neutral wind observed using meteor radar located at Mohe $\left(122.37^{\circ} \mathrm{E}, 53.50^{\circ} \mathrm{N}\right), \mathrm{Beijing}\left(116.25^{\circ} \mathrm{E}, 40.25^{\circ} \mathrm{N}\right), \mathrm{Wuhan}$ $\left(114.61^{\circ} \mathrm{E}, 30.53^{\circ} \mathrm{N}\right)$, and Sanya $\left(109.60^{\circ} \mathrm{E}, 18.30^{\circ} \mathrm{N}\right)$ during two SSW events (2011-2012 top panels, and 2012-2013 bottom panels). The warming onset is indicated by the red vertical dashed line. The 14.5-day period is marked with a red horizontal dashed line. The left column is meridional wind, and the right column is zonal wind (after Tang Q et al., 2020).

wavelength of about several hundred kilometers, a horizontal phase velocity of $50-230 \mathrm{~m} / \mathrm{s}$, and a period of $20-70 \mathrm{~min}$ (Shiokawa et al., 2003; Kotake et al., 2007; Ding F et al., 2011; Chen GY et al., 2019). The characteristics of MSTID have been revealed us- ing all-sky optical images and GNSS-TEC maps. According to longterm observations, MSTID can be categorized into daytime and nighttime forms (Figure 11). Daytime MSTID mainly occurs between 12-16 LT in winter hemispheres, and propagates to- 

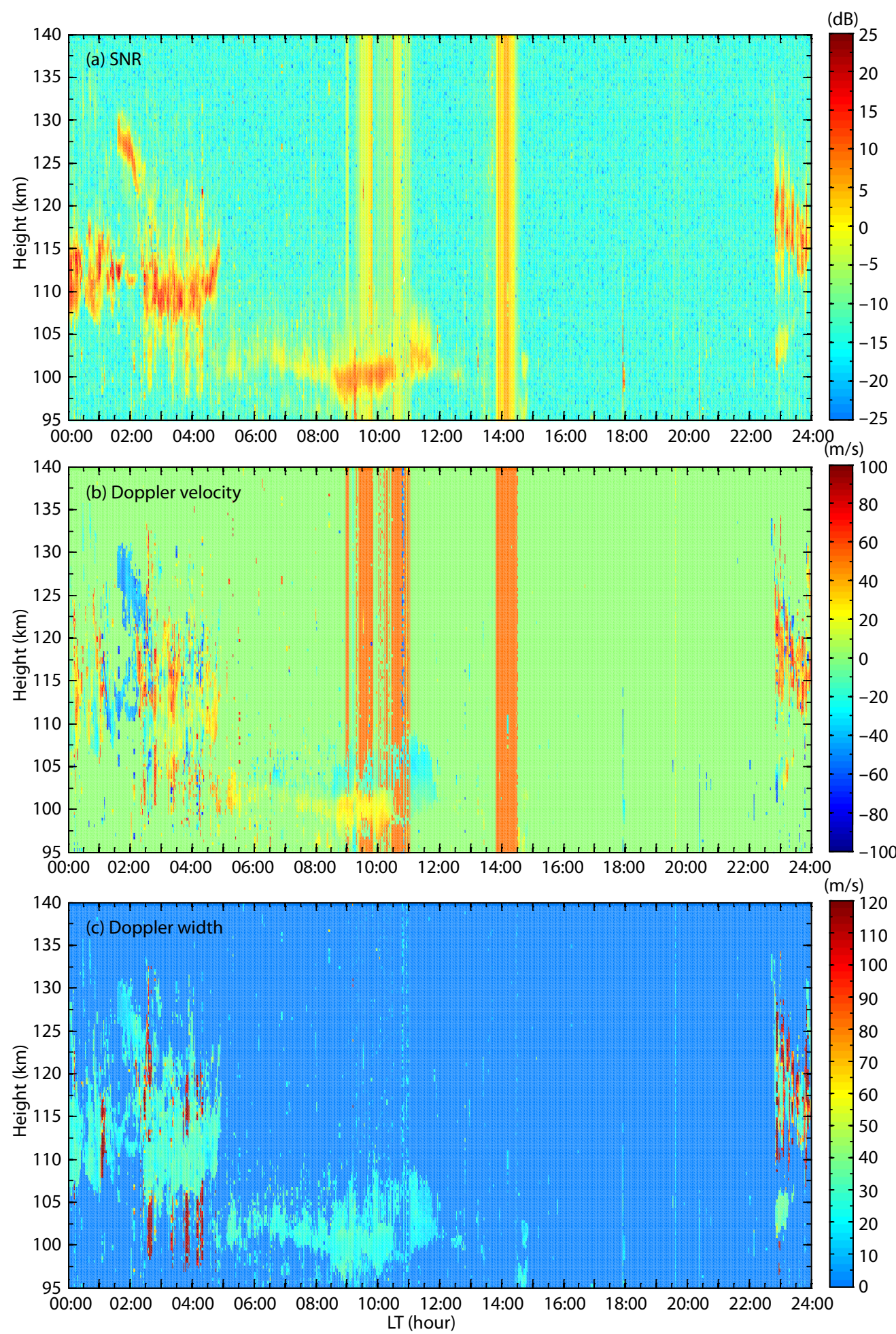

Figure 6. Example of E region FAls observed by Wuhan VHF radar in Wuhan (30.54 $\left.\mathrm{N}, 114.37^{\circ} \mathrm{E}\right)$ on June 17, 2016. (a) SNR, (b) Doppler Velocity, and (c) Doppler Width (after Zhou C et al., 2018a).

ward the equator. Conversely, nighttime MSTID mainly appears between 20-04 LT and reaches maximum in summer hemispheres. Most nighttime MSTIDs are aligned northwest-southeast (northeast-southwest) with preferential southwestward (northwestward) propagation in the northern (southern) hemisphere (Ding F et al., 2011; Martinis et al., 2019).
VHF radar data have revealed that there are FAl structures in the nighttime ionospheric $F$ layer. Recent observations showed a close relationship between FAI, SF, and MSTID in the mid-latitude nighttime ionosphere (Fukao et al., 1988, 1991; Bowman, 1990; Swartz et al., 2000; Saito et al., 2002; Otsuka et al., 2009; Sun LC et al., 2015; Liu $Y$ et al., 2019). The results of a joint observational experiment carried out in Wuhan are shown in Figure 12 (Liu Y et al., 


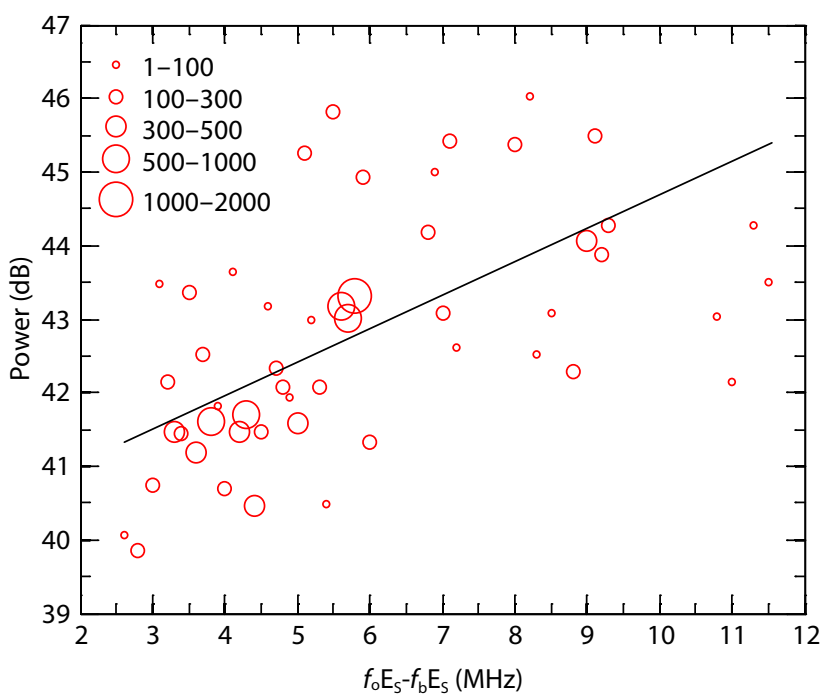

Figure 7. Correlation distribution between $\mathrm{E}$ region $\mathrm{FAl}$ echo power and $\mathrm{E}_{\mathrm{S}}$ density gradient $\left(f_{\mathrm{o}} \mathrm{E}_{\mathrm{S}}-f_{\mathrm{b}} \mathrm{E}_{\mathrm{S}}\right)$ (after Zhou $\mathrm{C}$ et al., 2018a).

2019). Nighttime F region FAI, SF, and MSTID could coexist and have some similar spatial and temporal distribution characteristics (Figure 12).

\subsection{Formation Mechanisms}

$F$ region irregularities at mid-latitudes are thought to originate through gravity wave theory (Hines, 1960; Hooke, 1968; Vadas,

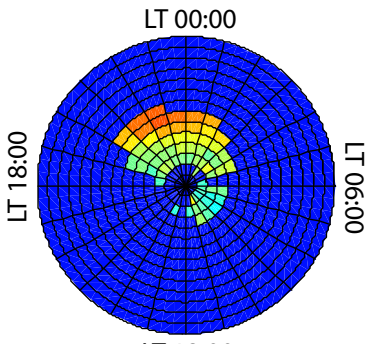

LT 12:00

(a) Doppler velocity

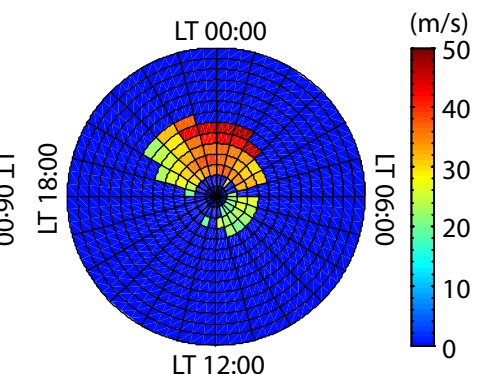

(b) Spectral width
Figure 8. Doppler spectrum of E region FAl echoes at Wuhan during 2015-2016. Distributions are binned as a function of local time and height from $90 \mathrm{~km}$ to $160 \mathrm{~km}$ in steps of $5 \mathrm{~km}$ (after Zhou C et al., 2018a).

2007). Bowman $(1990,1991)$ proposed that the generation of SF in this region is generally caused by the breaking of atmospheric gravity waves. Xiao et al. (2012) studied the ionospheric response to typhoons and concluded that SF could be triggered by upward propagating gravity waves during the typhoon period. Through the collision between ions and neutral particles, ionospheric plasma density disturbances could be driven by the upward propagation of gravity waves from the lower atmosphere. Further observational evidence supporting this theory is presented by Ding F et al. (2011) and Kotake et al. (2006). The consistency of cooccurring daytime MSTID and atmospheric gravity waves is presented in Figure 13. The dominantly equatorward propaga-
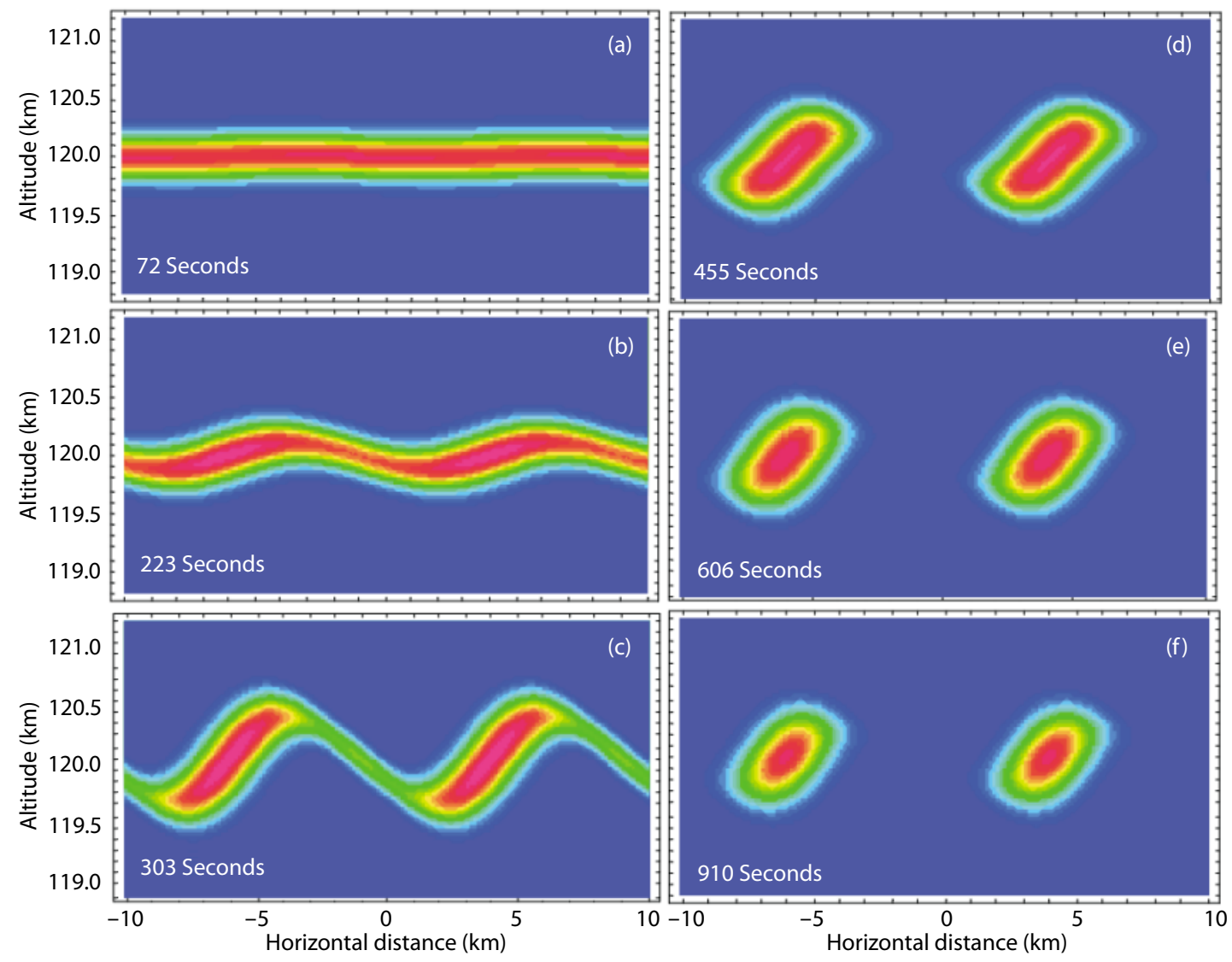

Figure 9. The simulated results of QP density irregularity structure in the E region produced by KHI (after Bernhardt, 2002). 

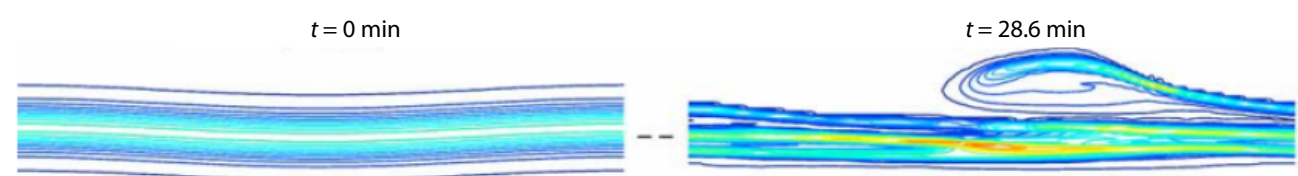

$t=2.2 \mathrm{~min}$
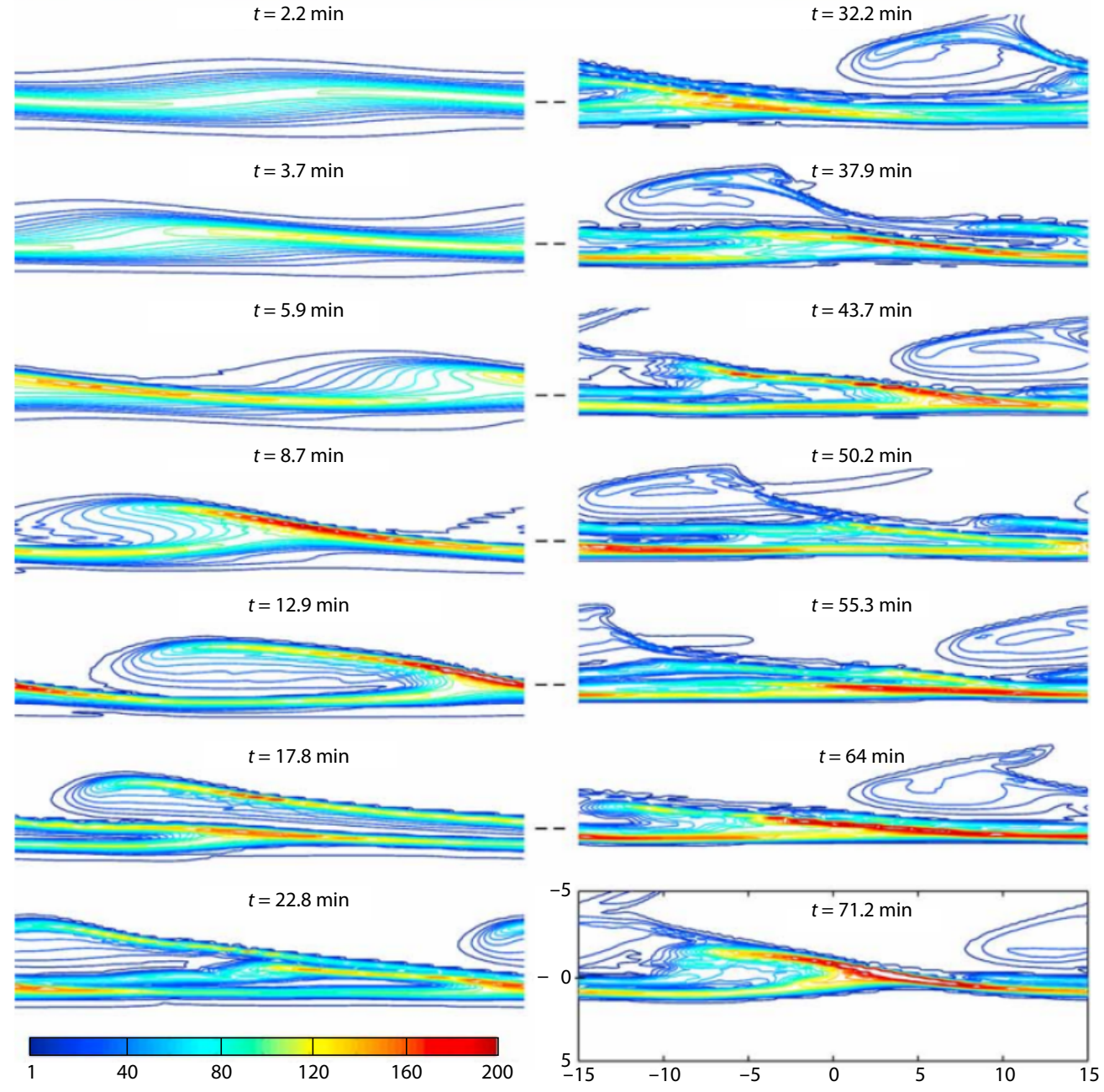

Figure 10. Simulation results of the evolution of $E$ region irregularity modulated by $E_{S}$-layer instability (after Cosgrove and Tsunoda, 2003).

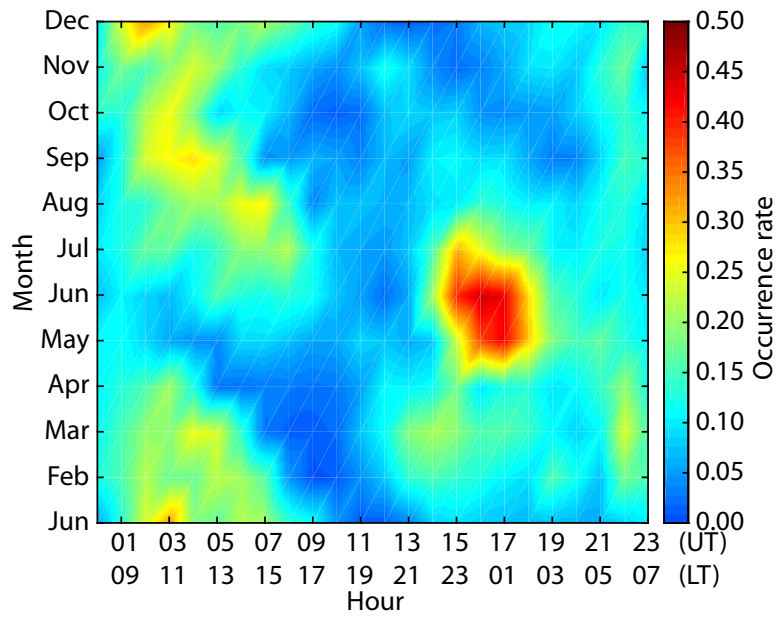

Figure 11. Local time-month distribution of MSTID occurrence rate in Hong Kong during the period of 2014-2017 (after Chen GY et al., 2019). tion of daytime MSTID could also be explained by gravity wave theory due to the fact that the oscillation of neutral particles is larger along the magnetic field direction for equatorward propagating atmospheric gravity waves than for those propagating in other directions, which are more likely to cause significant plasma density disturbances (Otsuka et al., 2013). However, the morphological characteristics of nighttime MSTID obviously do not conform to the modulation results of gravity waves, which suggests that other plasma instabilities may generate MSTID in the nighttime ionospheric F layer.

An electrodynamic instability in the $\mathrm{F}$ region, as proposed by Perkins (1973), is a possible mechanism for exciting nighttime MSTID and SF. Due to the modulation of the integral Hall conductivity along the magnetic field and height direction, nighttime plasma density structure becomes unstable in the $\mathrm{F}$ layer. When the wave vector direction of plasma density disturbance lies between the effective background electric field and geomagnetic east direction, a Perkins instability would be triggered, generating an ionospheric irregularity with a horizontal structure along the northw- 

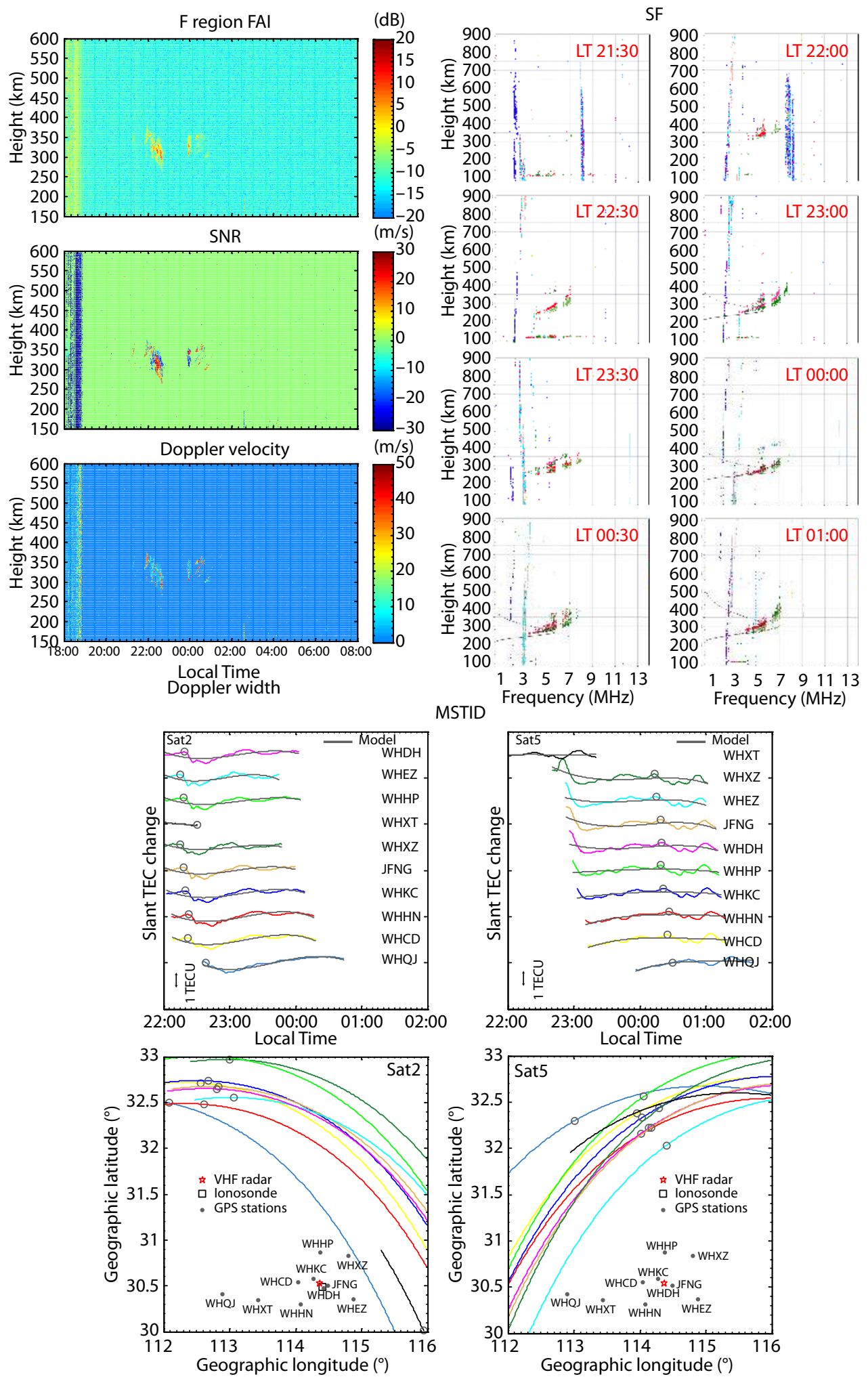

Figure 12. Simultaneous observations of different scale nighttime $F$ region irregularities at mid-latitudes based on joint observational experiments carried out in Wuhan (after Liu Y et al., 2019).

est-southeast direction in the northern hemisphere, explaining the observed horizontal structure of nighttime MSTID. The seasonal variations in nighttime MSTID could also be understood in terms of the linear growth rate of the Perkins instability (Hamza, 1999; Kelley, 2009). The statistical analysis of SF occurrence presented in Candido et al. (2011) and Paul et al. (2019) demonstrates that MSTID related to the Perkins instability plays an important role in SF development. Jiang CH et al. (2019) reconstructed the ionograms during TID using ray tracing and further verified that ionospheric density wave structure leads to SF. Yokoy- 

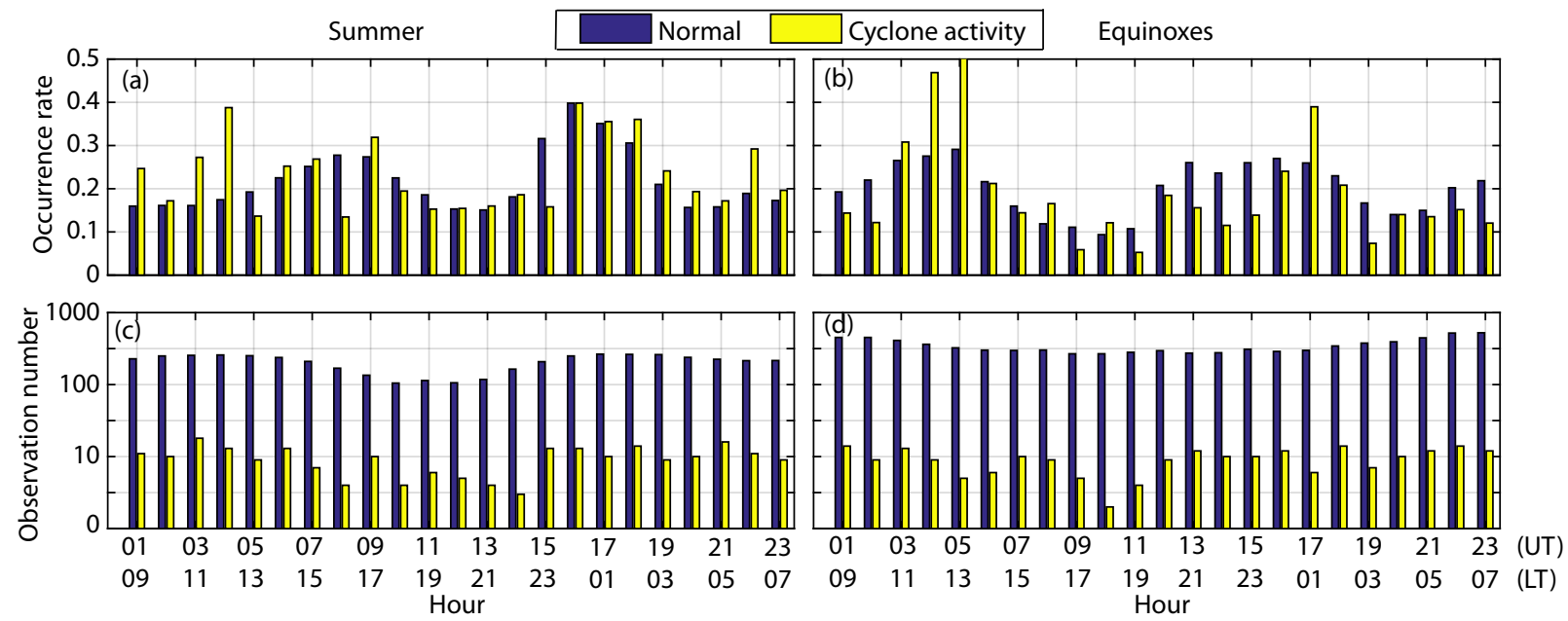

Figure 13. Local time variation of MSTID occurrence rate under different atmospheric activity conditions (after Chen GY et al., 2019).

ama et al. (2008) first produced a 3-D numerical model of the Perkins instability and simulated the evolution of the nighttime $F$ layer plasma density irregularity. However, the Perkins instability cannot fully explain all the observed characteristics of nighttime MSTID at mid-latitudes. The excessively small linear growth rate (on the order of $\sim 10^{-4} \mathrm{~s}^{-1}$ ) is completely inconsistent with the observations to date (Kelley and Fukao, 1991; Garcia et al., 2000). On the other hand, according to the Perkins instability mechanism, the wave structure excited by the instability propagates in the same direction as the background $E \times B$ drift at night, generally moving southeast in the northern hemisphere, contrary to the observations of nighttime MSTID (Makela and Otsuka, 2011). This suggests that there are other possible mechanisms generating nighttime MSTID at mid-latitudes in conjunction with the Perkins instability.

At present, the Perkins instability mechanism explains the formation of large-scale ( $>50 \mathrm{~km}$ ) nighttime ionospheric $\mathrm{F}$ region irregularities at mid-latitudes, but there are still some problems in understanding the formation of small-scale structures. Basu et al. (1981) proposed that GDI might be the main reason for the formation of small-scale irregularities in the nighttime ionosphere at mid-latitudes. Based on MU radar observations, $\mathrm{F}$ region $\mathrm{FAI}$ echoes mainly appeared in the area where the plasma density gradient moves upward at the bottom of the F layer (Kelley and Fukao, 1991; Saito et al., 2002; Otsuka et al., 2009). Figure 14 illustrates the evolution of different scales of irregularity structures in the nighttime ionosphere. When there is the right direction of electric field or neutral wind in the nighttime ionospheric $F$ region, the Perkins instability is triggered and excites MSTID. Under these conditions, MSTID in the electron density depletion areas could be further modulated by $E \times B$ drift through secondary plasma instability (GDI) and excited kilometer scale structure, which eventually evolves into meter scale irregularity through a nonlinear cascade process. Theoretical analysis shows that the duration of meter-scale FAI is related to $\left(k^{2} D_{\mathrm{p}}\right)^{-1}$, where $k$ is the wave vector size of small-scale plasma waves and $D_{\mathrm{p}}$ is the electron diffusion coefficient in the direction perpendicular to the magnetic field (Mathews et al., 2001). The calculated time scale is 0.02-0.2 s; thus, it is impossible for meter scale structure to exist alone for such a short duration, which is also confirmed by the joint observational experiment (Figure 12).

\section{Ionospheric Electrodynamic Coupling}

As mentioned in Sections 2 and 3, the formation of ionospheric irregularities in the $\mathrm{E}$ and $\mathrm{F}$ regions is closely related to electrodynamic processes, and the polarized electric field plays a significant role in the development of plasma instabilities (Tsunoda et al., 1994; Haldoupis et al., 1996; Yokoyama et al., 2003, 2004a, b). At mid-latitudes, a polarized electric field can map to different ionospheric regions, leading to ionospheric electrodynamics in the $E$ and $F$ regions that can influence each other along the magnetic field lines (Figure 15). Thus, ionospheric E-F coupling may affect the formation of plasma density irregularities in the $E$ and $F$ regions (Zhou C et al., 2018b; Liu Y et al., 2019, 2020). Moreover, the effect of ionospheric inter-hemispheric coupling on the formation of $\mathrm{F}$ region irregularities is evident in magnetic conjugate observations (Otsuka et al., 2004; Martinis et al., 2010; Duly et al., 2014; Burke et al., 2016; Valladares and Sheehan, 2016). Next, we review recent research on ionospheric electrodynamic coupling in the mid-latitude region.

\subsection{Ionospheric E-F Coupling}

lonospheric E-F coupling was first reported by Bowman (1960). Subsequently, a large number of joint observational experiments have confirmed that ionospheric E-F coupling phenomena frequently occur in the nighttime ionosphere at mid-latitudes (Haldoupis et al., 2003; Otsuka et al., 2007; Hysell et al., 2018; Zhou C et al., 2018b; Liu Y et al., 2019, 2020). Figure 16 shows an example of ionospheric E-F coupling using VHF radar, ionosonde, and all-sky optical images around Wuhan. The observed $E_{S}, S F, E$ region FAI echoes, and MSTIDs occurred simultaneously in the nighttime ionosphere (Zhou C et al., 2018b). As shown in Figure 17, the COSMIC data first elucidated the coexistence of nighttime plasma density disturbance structures in both $E$ and $F$ regions in both hemispheres (Liu Y et al., 2020). The statistical characteristics of ionospheric E-F coupling phenomena were also described by Zhou C et al. (2018b) and Liu Y et al. (2020). 


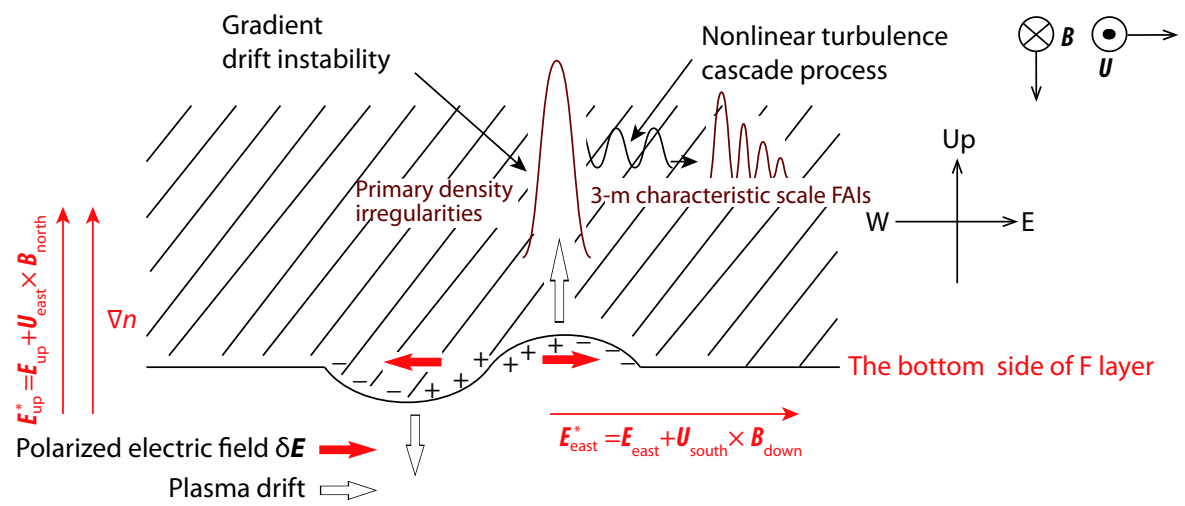

Figure 14. Schematic diagram showing the evolution process for different scale ionospheric irregularity structures (after Liu Y et al., 2019).
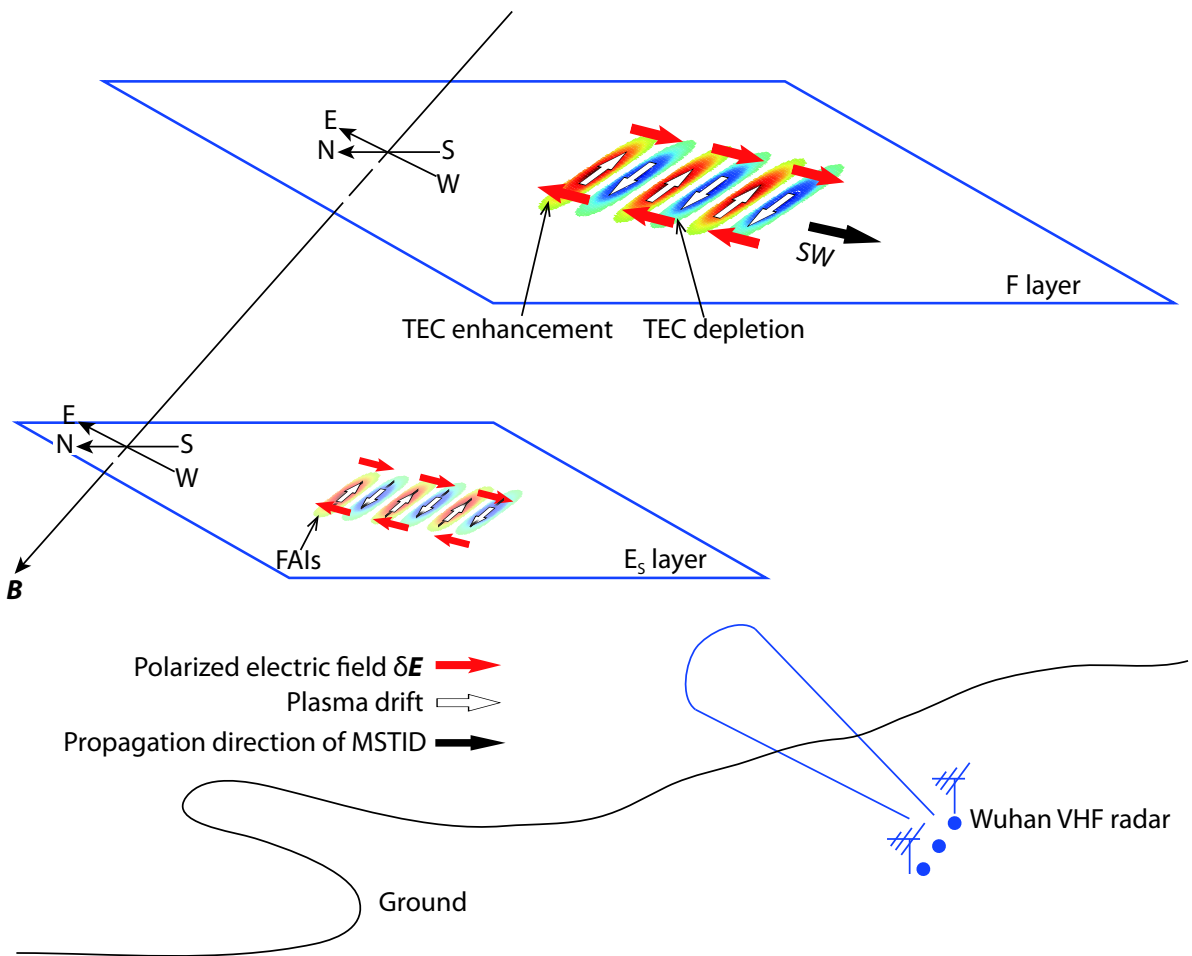

Figure 15. Schematic diagram showing the nighttime ionospheric E-F coupling process (after Liu Y et al., 2019).

As mentioned above, researchers have noticed the close relationship between $\mathrm{F}$ region plasma density disturbance and $\mathrm{E}_{\mathrm{S}}$ structure since 1960. Theoretical modelling by Farley $(1959,1960)$ has indicated that an electric field with a certain spatial scale can map between $E$ and $F$ regions due to its high conductivity along magnetic field lines. Based on the research of Haldoupis et al. (1996), Tsunoda and Cosgrove (2001) further explained the mechanism generating polarized electric fields in the nighttime ionosphere at mid-latitudes, and proposed that there might be a positive feedback loop between $E_{S}$ structures and $F$ region irregularities. Cosgrove and Tsunoda (2004) first derived the linear growth rate of the coupling mechanism including $E_{S}$-layer instability and Perkins instability, suggesting that the growth rate of coupling was much larger than that of a single instability, conducive to the formation and development of ionospheric irregularities. Figure 18 shows the first 3-D numerical model for studying the ionospheric E-F coupling process, illustrating the importance of polarized electric fields in plasma irregularities (Yokoyama et al., 2009).

It is clear that the existence of $E_{S}$ is not always accompanied by ionospheric E-F coupling (Liu Y et al., 2020). Farley (1959, 1960) proposed that the mapping efficiency of an electric field depends on its spatial scale and ionospheric background conductivity. Electric fields with a spatial scale larger than $10 \mathrm{~km}$ can map without loss from the $\mathrm{E}$ layer to the $\mathrm{F}$ layer. In addition, the mapping efficiency of electric fields is also affected by the integrated Pedersen conductivity of the $\mathrm{F}$ region $\left(\sum_{p}^{F}\right)$, and is negatively correlated with the order of $\sum_{P}^{F}$. Recent numerical simulations have successfully reproduced the effect of ionospheric conductivity on the occurrence of ionospheric irregularities (Yokoyama et al, 2004b; Cosgrove, 2007).

\subsection{Ionospheric Inter-Hemispheric Coupling}

The coexistence of plasma density disturbances has been ob- 

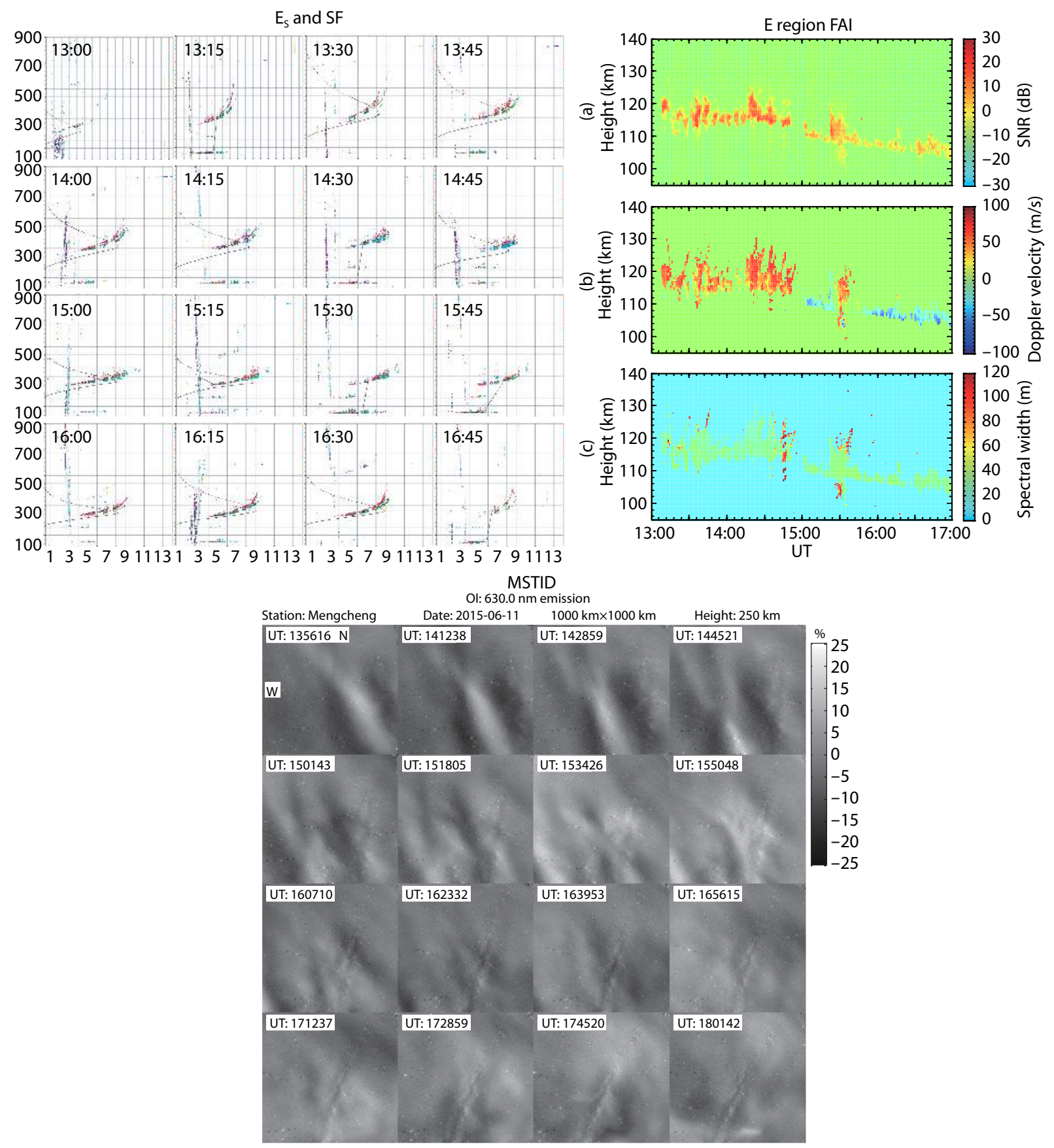

Figure 16. An example of joint observational experiments carried out around Wuhan by using ionosonde, VHF radar, and all-sky optical images (after Zhou C et al., 2018b).

served in the nighttime ionospheric $\mathrm{F}$ layer in magnetic conjugate regions (Figure 19). Otsuka et al. (2004) first observed the simultaneous occurrence of nighttime MSTID structures by using two all-sky optical imagers in the magnetic conjugate areas. Their results suggested that the local polarized electric field would be excited during MSTID and map to the conjugate ionosphere along magnetic field lines, which could induce plasma density disturbances through electrodynamic processes (Figure 20). Nighttime F region electric field fluctuations have been observed at magnetic conjugate points using incoherent scatter radar and the DE2 satellite (Burnside et al., 1983). The statistical characteristics of magnet- ic conjugate observations of nighttime $F$ region irregularities were first reported by Liu Y et al. (2020) using COSMIC satellites, which further demonstrated the importance of ionospheric inter-hemispheric coupling in generating ionospheric irregularities. Corresponding numerical simulation models have also been developed to study the ionospheric inter-hemispheric coupling process (Duly et al., 2014; Yokoyama, 2014).

\section{Summary}

In this paper, we reported on recent developments in the understanding of ionospheric irregularities in the $E$ and $F$ regions at 


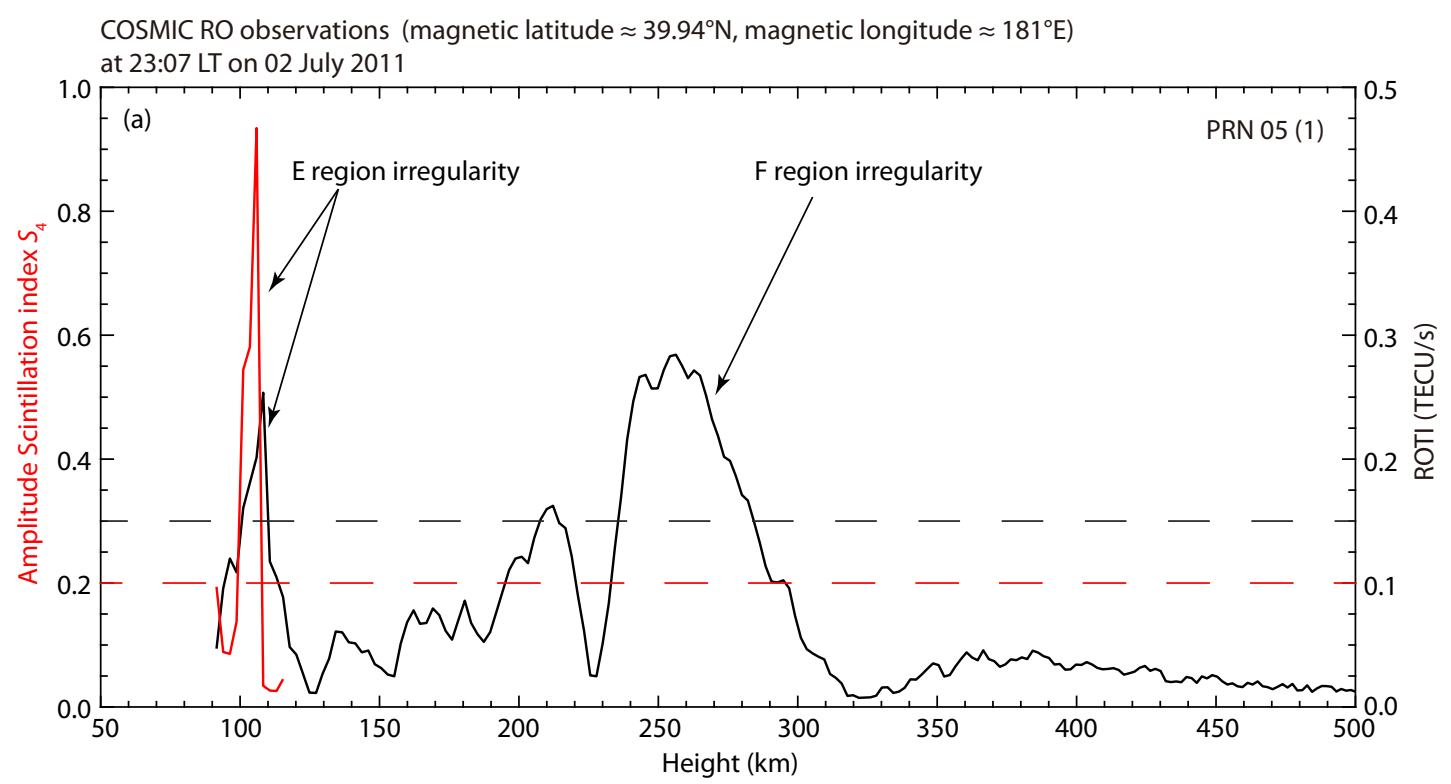

COSMIC RO observations (magnetic latitude $\approx 31.67^{\circ} \mathrm{S}$, magnetic longitude $\approx 176^{\circ} \mathrm{E}$ )

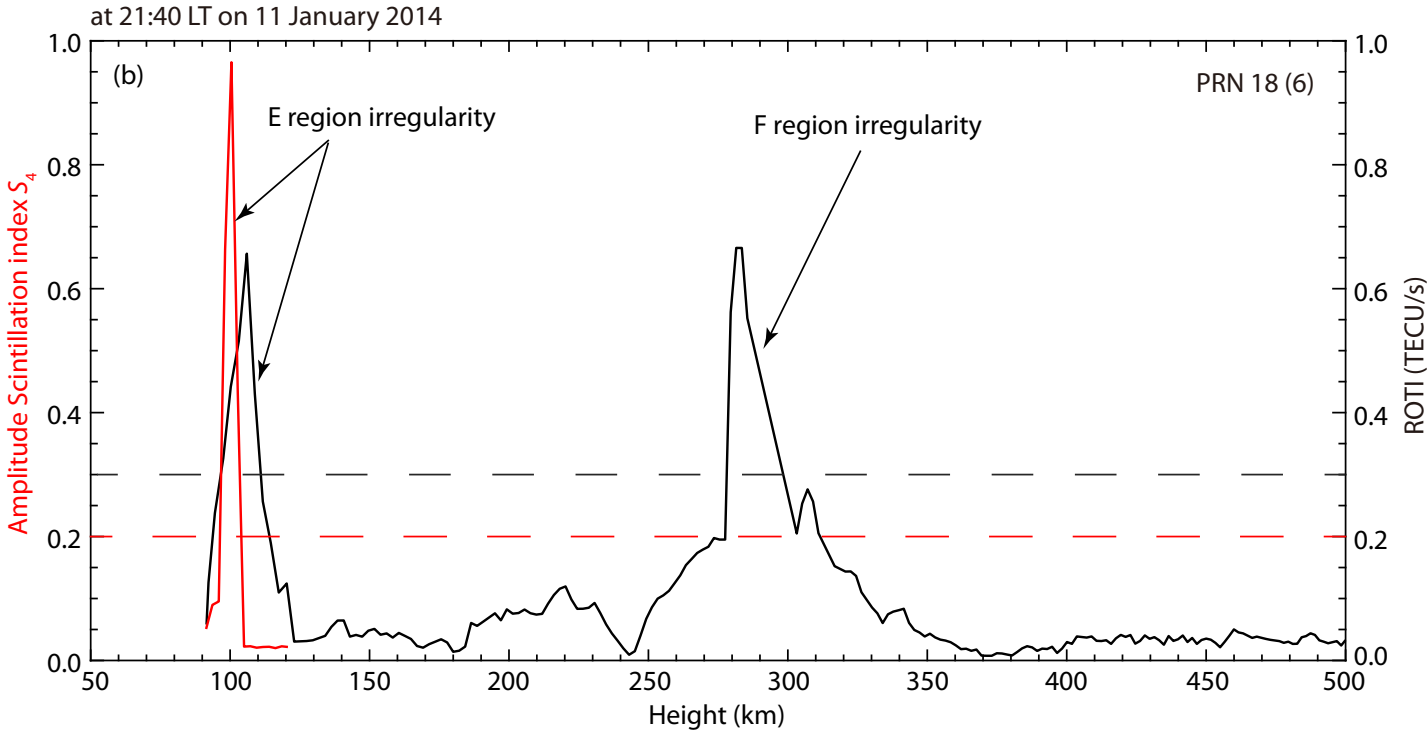

Figure 17. Examples of ionospheric irregularities in the $E$ and $F$ regions observed by COSMIC satellites at (a) 23:07 LT on 02 July 2011 in the northern hemisphere, and (b) at 21:40 LT on 11 January 2014 in the southern hemisphere (after Liu Y et al., 2020).

mid-latitudes and discussed the importance of ionospheric electrodynamic processes in generating ionospheric irregularities. The main points are summarized as follows:

\subsection{E Region Irregularity}

$E_{S}$ and $E$ region $\mathrm{FAl}$ are predominantly observed in the $\mathrm{E}$ region at mid-latitudes. The typical morphological features of $E_{S}$ and $E$ region $\mathrm{FAl}$ are:

1) $E_{S}$ occurrence reaches a maximum $\sim 14$ LT and a secondary maximum at $\sim 20 \mathrm{LT}$, while $\mathrm{E}$ region FAI mainly occurs after sunset. 2) Atmospheric wave components can be clearly observed in $E_{S}$ layer distribution.

3) Spectrum features of E region FAl echoes show that type-2 irregularities are dominant in the nighttime ionosphere.

4) A strong correlation exists between $E_{S}$ layer and $E$ region $F A I$ structures. The seasonal variations of $E_{S}$ and $E$ region $\mathrm{FAl}$ occurrence have a similar distribution, with a maximum in summer (winter) in the northern (southern) hemisphere.

5) The effect of magnetic activity on E region irregularity occurrence is complex and varies with latitude, longitude, and local time.

6) The factors generating $E$ region irregularity are neutral wind and electrical fields. Zonal wind shear can drive metallic ions to converge and excite large polarized electric fields at night, resulting in plasma instabilities and the generation of $\mathrm{E}$ region irregularities at mid-latitudes.

\subsection{F Region Irregularity}

Plasma density irregularities are frequently observed in the nighttime $\mathrm{F}$ region. A close relationship across different scales of ionospheric $F$ region irregularities has been demonstrated in joint ob- 

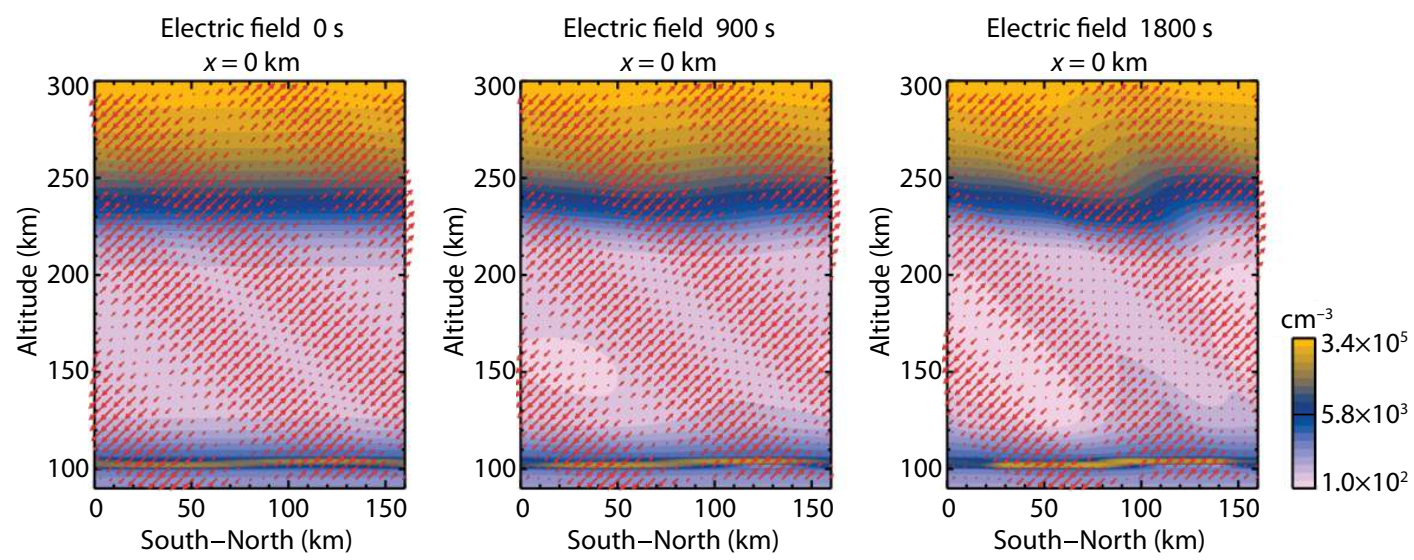

Figure 18. Simulation results of the coupled Perkins instability and $\mathrm{E}_{\mathrm{S}}$-layer instability in the nighttime ionosphere at mid-latitudes (after Yokoyama et al., 2009).

COSMIC RO observations in the same magnetic meridian plane (magnetic longitude $\approx 193^{\circ} \mathrm{E}$ ) on 31 January 2007
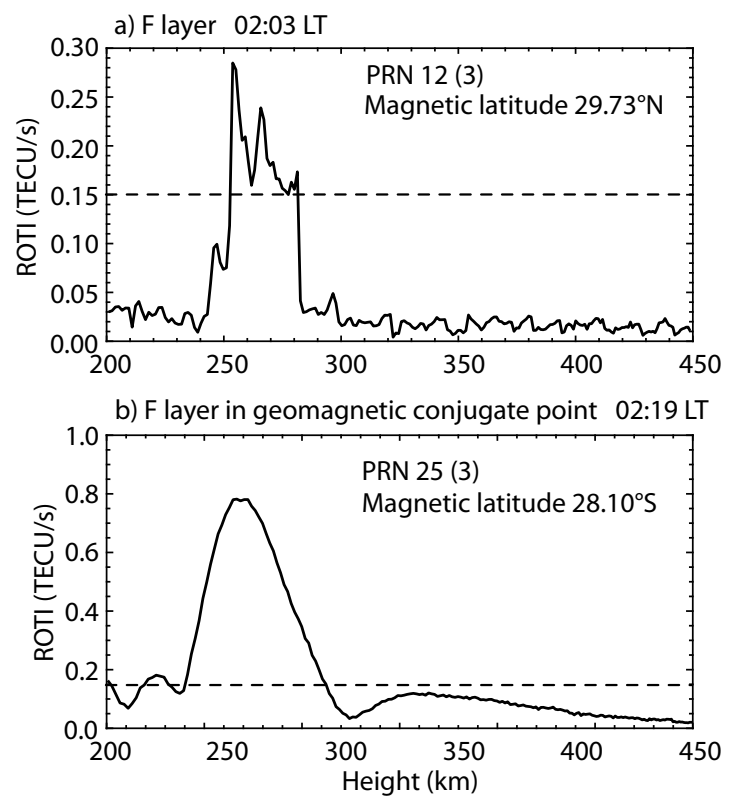

(a)
COSMIC RO observations in the same magnetic meridian plane (magnetic longitude $\approx 176^{\circ} \mathrm{E}$ ) on 14 June 2007

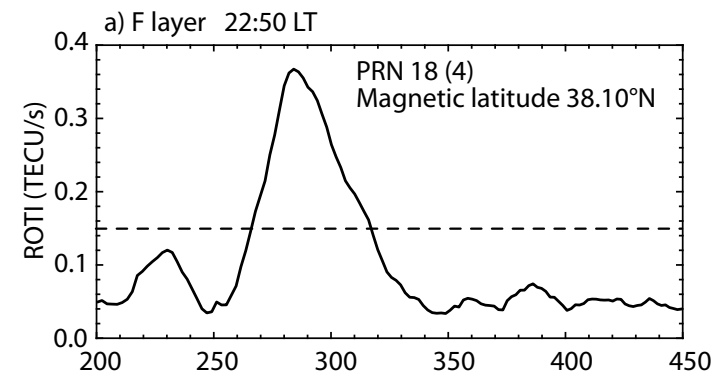

b) F layer in geomagnetic conjugate point 23:11 LT

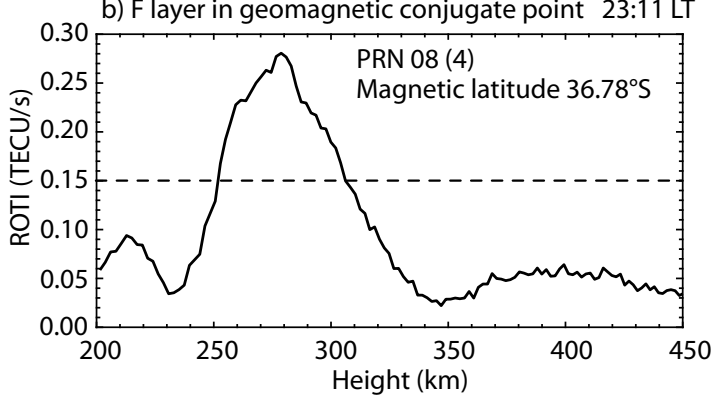

(b)

Figure 19. Examples of nighttime ionospheric $\mathrm{F}$ region irregularities in conjugate hemispheres observed by COSMIC satellites (a) on 31 January 2007 and (b) on 14 June 2007 (after Liu Y et al., 2020).

servational experiments. Plasma instabilities play a significant role in the development and evolution of ionospheric irregularity structures from large scale to small scale. The polarized electric field excited by the Perkins instability during nighttime MSTID can further modulate plasma density disturbances through $E \times B$ drift where the electron density gradient is upward and drives GDI to form small scale structures which finally evolve into smaller scale structures through nonlinear cascade processes.

\subsection{Ionospheric Electrodynamic Coupling}

Due to the significant dip angle and equipotentiality of magnetic field lines in the mid-latitude ionosphere, electric fields can map to different ionospheric regions and affect electrodynamic processes for generating plasma density irregularities. The importance of ionospheric E-F coupling and inter-hemispheric coupling is revealed using various joint observational experiments. In addition, the spatial scale of electric fields and ionospheric background parameters, such as conductivity (the integrated Hall conductivity of $E_{S}$ layer $\left(\sum_{H}^{E_{S}}\right)$ and $\left.\sum_{p}^{F}\right)$, play important roles in the mapping efficiency of electrodynamic coupling.

\section{Acknowledgments}

We acknowledge numerous colleagues for kindly providing their articles and figures for this brief review. This work was supported by the National Natural Science Foundation of China (No. 41574146, 41774162, 42074187), the National Key R\&D Program of China (No. 2018YFC1503506), the Excellent Youth Foundation of Hubei Provincial Natural Science Foundation (No. 2019CFA054), and the Foundation of the National Key Laboratory of Electromagnetic Environment (No. 20200101). 
(a) Sata

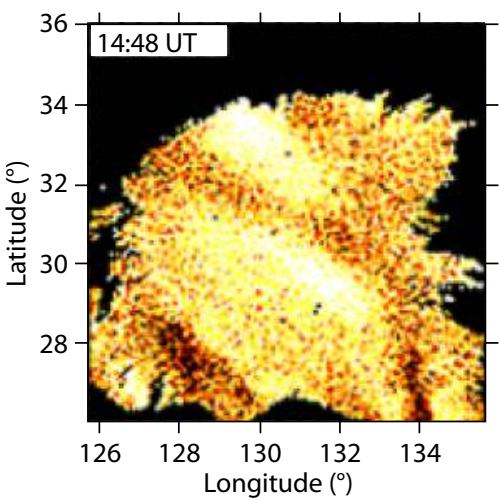

(b) Darwin

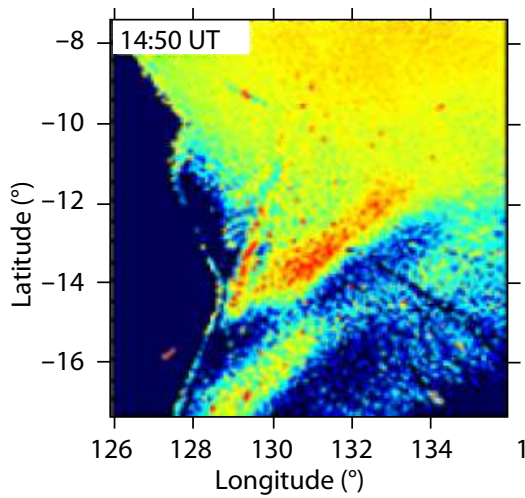

(c) Sata (left) and conjugate of Darwin (right)

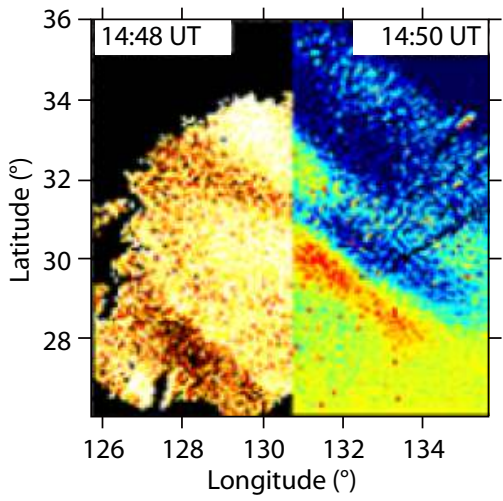

Aug. 9. 2002 (630 $\mathrm{nm}$ airglow)
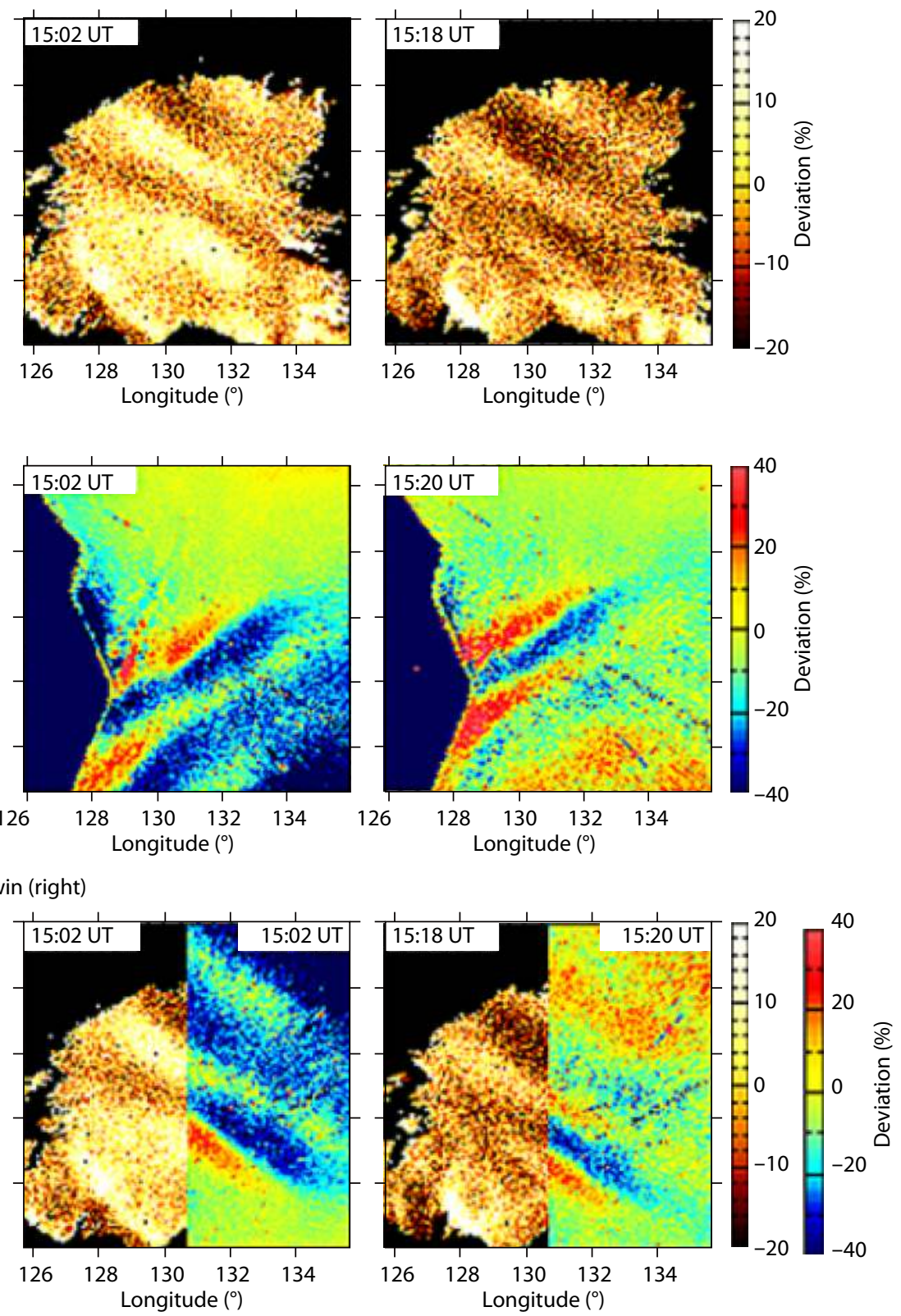

Figure 20. Simultaneous observations of nighttime MSTID structures using two all-sky optical imagers for magnetic conjugate areas at midlatitudes (after Otsuka et al., 2004).

\section{References}

Abdu, M. A., Batista, I. S., and Bittencourt, J. A. (1981). Some characteristics of spread $\mathrm{F}$ at the magnetic equatorial station Fortaleza. J. Geophys. Res. 86(A8), 6836-6842. https://doi.org/10.1029/ja086ia08p06836

Abdu, M. A., Sobral, J. H. A., Nelson, O. R., and Batista, I. S. (1985). Solar cycle related range type spread- $F$ occurrence characteristics over equatorial and low latitude stations in Brazil. J. Atmos. Terr. Phys., 47(8-10), 901-905. https://doi.org/10.1016/0021-9169(85)90065-0

Abdu, M. A. (2001). Outstanding problems in the equatorial ionospherethermosphere electrodynamics relevant to spread F. J. Atmos. Sol. Terr. Phys., 63(9), 869-884. https://doi.org/10.1016/S1364-6826(00)00201-7

Abdu, M. A., Souza, J. R., Batista, I. S., Fejer, B. G., and Sobral, J. H. A. (2013). Sporadic $E$ layer development and disruption at low latitudes by prompt penetration electric fields during magnetic storms. J. Geophys. Res., 118(5), 2639-2647. https://doi.org/10.1002/jgra.50271
Abdu, M. A., De Souza, J. R., Batista, I. S., Santos, A. M., Sobral, J. H. A., Rastogi, R. G., and Chandra, H. (2014). The role of electric fields in sporadic E layer formation over low latitudes under quiet and magnetic storm conditions. $J$. Atmos. Sol. Terr. Phys., 115-116, 95-105. https://doi.org/10.1016/j.jastp.2013.12.003

Arras, C., Wickert, J., Beyerle, G., Heise, S., Schmidt, T., and Jacobi, C. (2008). A global climatology of ionospheric irregularities derived from GPS radio occultation. Geophys. Res. Lett., 35(14), L14809. https://doi.org/10.1029/2008GL034158

Basu, S., and Kelley, M. C. (1979). A review of recent observations of equatorial scintillations and their relationship to current theories of $F$ region irregularity generation. Radio Sci., 14(3), 471-485. https://doi.org/10.1029/RS014i003p00471

Basu, S., Basu, S., Ganguly, S., and Klobuchar, J. A. (1981). Generation of kilometer scale irregularities during the midnight collapse at Arecibo. J. 
Geophys. Res., 86(A9), 7607-7616. https://doi.org/10.1029/JA086iA09p07607

Basu, S., MacKenzie, E., and Basu, S. (1988). Ionospheric constraints on VHF/UHF communications links during solar maximum and minimum periods. Radio Sci., 23(3), 363-378. https://doi.org/10.1029/RS023i003p00363

Bernhardt, P. A. (2002). The modulation of sporadic-E layers by KelvinHelmholtz billows in the neutral atmosphere. J. Atmos. Sol. Terr. Phys., 64(1214), 1487-1504. https://doi.org/10.1016/S1364-6826(02)00086-X

Booker, H. G., and Wells, H. W. (1938). Scattering of radio waves by the F-region of the ionosphere. J. Geophys. Res., 43(3), 249-256. https://doi.org/10.1029/TE043i003p00249

Bowman G. G. (1960). Some aspects of sporadic- $E$ at mid-latitudes. Planet. Space Sci., 2(4), 195-202. https://doi.org/10.1016/0032-0633(60)90016-7

Bowman, G. G. (1990). A review of some recent work on mid-latitude spread- $F$ occurrence as detected by ionosondes. J. Geomagn. Geoelectr., 42(2), 109-138. https://doi.org/10.5636/jgg.42.109

Bowman, G. G. (1991). Ionospheric frequency spread and its relationship with range spread in mid-latitude regions. J. Geophys. Res., 96(A6), 9745-9753. https://doi.org/10.1029/91JA00389

Burke, W. J., Martinis, C. R., Lai, P. C., Gentile, L. C., Sullivan, C., and Pfaff, R. F. (2016). C/NOFS observations of electromagnetic coupling between magnetically conjugate MSTID structures. J. Geophys. Res., 121(3), 2569-2582. https://doi.org/10.1002/2015JA021965

Burnside, R. G., Walker, J. C. G., Behnke, R. A., and Gonzales, C. A. (1983). Polarization electric fields in the nighttime F layer at Arecibo. J. Geophys. Res., 88(A8), 6259-6266. https://doi.org/10.1029/JA088iA08p06259

Candido, C. M. N., Batista, I. S., Becker-Guedes, F., Abdu, M. A., Sobral, J. H. A., and Takahashi, H. (2011). Spread F occurrence over a southern anomaly crest location in Brazil during June solstice of solar minimum activity. J. Geophys. Res., 116(A6), A06316. https://doi.org/10.1029/2010JA016374

Chen, G. Y., Zhou, C., Liu, Y., Zhao, J. Q., Tang, Q., Wang, X., and Zhao, Z. Y. (2019). A statistical analysis of medium-scale traveling ionospheric disturbances during 2014-2017 using the Hong Kong CORS network. Earth Planets Space, 71(1), 52. https://doi.org/10.1186/s40623-019-1031-9

Chu, Y. H., Wang, K. H., Wu, K. H., Chen, K. T., Tzeng, K. J., Su, C. L., and Plane, J. M. C. (2014). Morphology of sporadic $E$ layer retrieved from COSMIC GPS radio occultation measurements: Wind shear theory examination. J. Geophys. Res., 119(3), 2117-2136. https://doi.org/10.1002/2013JA019437

Cohen, R., and Bowles, K. L. (1967). Secondary irregularities in the equatorial electrojet. J. Geophys. Res., 72(3), 885-894. https://doi.org/10.1029/JZ072i003p00885

Cosgrove, R. B., and Tsunoda, R. T. (2001). Polarization electric fields sustained by closed-current dynamo structures in midlatitude sporadic E. Geophys. Res. Lett., 28(8), 1455-1458. https://doi.org/10.1029/2000GL012178

Cosgrove, R. B., and Tsunoda, R. T. (2002a). Wind-shear-driven, closed-current dynamos in midlatitude sporadic E. Geophys. Res. Lett., 29(2), 1020. https://doi.org/10.1029/2001GL013697

Cosgrove, R. B., and Tsunoda, R. T. (2002b). A direction-dependent instability of sporadic-E layers in the nighttime midlatitude ionosphere. Geophys. Res. Lett., 29(18), 1864. https://doi.org/10.1029/2002GL014669

Cosgrove, R. B., and Tsunoda, R. T. (2003). Simulation of the nonlinear evolution of the sporadic- $E$ layer instability in the nighttime midlatitude ionosphere. J. Geophys. Res., 108(A7), 1283. https://doi.org/10.1029/2002JA009728

Cosgrove, R. B., and Tsunoda R. T. (2004). Instability of the $E-F$ coupled nighttime midlatitude ionosphere. J. Geophys. Res., 109(A4), A04305. https://doi.org/10.1029/2003JA010243

Cosgrove, R. B. (2007). Generation of mesoscale $F$ layer structure and electric fields by the combined Perkins and ES layer instabilities, in simulations. Ann. Geophys., 25(7), 1579-1601. https://doi.org/10.5194/angeo-25-1579-2007

Dabas, R. S., Das, R. M., Sharma, K., Garg, S. C., Devasia, C. V., Subbarao, K. S. V., and Rama Rao, P. V. S. (2007). Equatorial and low latitude spread-F irregularity characteristics over the Indian region and their prediction possibilities. J. Atmos. Sol. Terr. Phys., 69(6), 685-696. https://doi.org/10.1016/j.jastp.2007.01.002

Ding, F., Wan, W. X., Xu, G. R., Yu, T., Yang, G. L., and Wang, J. S. (2011). Climatology of medium-scale traveling ionospheric disturbances observed by a GPS network in central China. J. Geophys. Res., 116(A9), A09327.
https://doi.org/10.1029/2011JA016545

Duly, T. M., Huba, J. D., and Makela, J. J. (2014). Self-consistent generation of MSTIDs within the SAMI3 numerical model. J. Geophys. Res., 119(8), 6745-6757. https://doi.org/10.1002/2014JA020146

Dungey J. W. (1956). Convective diffusion in the equatorial $F$ region. J. Atmos. Terr. Phys., 9(5-6), 304-310. https://doi.org/10.1016/0021-9169(56)90148-9

Farley, D. T. Jr. (1959). A theory of electrostatic fields in a horizontally stratified ionosphere subject to a vertical magnetic field. J. Geophys. Res., 64(9), 1225-1233. https://doi.org/10.1029/JZ064i009p01225

Farley, D. T. Jr. (1960). A theory of electrostatic fields in the ionosphere at nonpolar geomagnetic latitudes. J. Geophys. Res., 65(3), 869-877. https://doi.org/10.1029/JZ065i003p00869

Farley, D. T. Jr. (1963). A plasma instability resulting in field-aligned irregularities in the ionosphere. J. Geophys. Res., 68(22), 6083-6097. https://doi.org/10.1029/JZ068i022p06083

Fejer, B. G., and Kelley, M. C. (1980). lonospheric irregularities. Rev. Geophys., 18(2), 401-454. https://doi.org/10.1029/RG018i002p00401

Fukao, S., McClure, J. P., Ito, A., Sato, T., Kimura, I., Tsuda, T., and Kato, S. (1988). First VHF radar observation of midlatitude F-region field-aligned irregularities. Geophys. Res. Lett., 15(8), 768-771. https://doi.org/10.1029/GL015i008p00768

Fukao, S., Kelley, M. C., Shirakawa, T., Takami, T., Yamamoto, Y., Tsuda, T., and Kato, S. (1991). Turbulent upwelling of the mid-latitude ionosphere: 1. Observational results by the MU radar. J. Geophys. Res., 96(A3), 3725-3746. https://doi.org/10.1029/90JA02253

Garcia, F. J., Kelley, M. C., Makela, J. J., and Huang, C. S. (2000). Airglow observations of mesoscale low-velocity traveling ionospheric disturbances at midlatitudes. J. Geophys. Res., 105(A8), 18407-18415. https://doi.org/10.1029/1999JA000305

Haldoupis, C., and Schlegel, K. (1996). Characteristics of midlatitude coherent backscatter from the ionospheric $E$ region obtained with Sporadic $E$ Scatter experiment. J. Geophys. Res., 101(A6), 13387-13397. https://doi.org/10.1029/96JA00758

Haldoupis, C., Schlegel, K., and Farley, D. T. (1996). An explanation for type 1 radar echoes from the midlatitude E-region ionosphere. Geophys. Res. Lett., 23(1), 97-100. https://doi.org/10.1029/95GL03585

Haldoupis, C., Kelley, M. C., Hussey, G. C., and Shalimov, S. (2003). Role of unstable sporadic- $E$ layers in the generation of midlatitude spread $F$.J. Geophys. Res., 108(A12), 1446. https://doi.org/10.1029/2003JA009956

Haldoupis, C., Pancheva, D., and Mitchell, N. J. (2004). A study of tidal and planetary wave periodicities present in midlatitude sporadic $E$ layers. J. Geophys. Res., 109(A2), A02302. https://doi.org/10.1029/2003JA010253

Haldoupis, C., Meek, C., Christakis, N., Pancheva, D., and Bourdillon, A. (2006). lonogram height-time-intensity observations of descending sporadic $E$ layers at mid-latitude. J. Atmos. Sol. Terr. Phys., 68(3-5), 539-557. https://doi.org/10.1016/j.jastp.2005.03.020

Haldoupis, C., Pancheva, D., Singer, W., Meek, C., and MacDougall, J. (2007). An explanation for the seasonal dependence of midlatitude sporadic $E$ layers. J. Geophys. Res., 112(A6), A06315. https://doi.org/10.1029/2007JA012322

Haldoupis, C. (2012). Midlatitude sporadic E. A typical paradigm of atmosphereionosphere coupling. Space Sci. Rev., 168(1-4), 441-461. https://doi.org/10.1007/s11214-011-9786-8

Hamza, A. M. (1999). Perkins instability revisited. J. Geophys. Res., 104(A10), 22567-22575. https://doi.org/10.1029/1999JA900307

Hines, C. O. (1960). Internal atmospheric gravity waves at ionospheric heights. Can. J. Phys., 38(11), 1441-1481. https://doi.org/10.1139/p60-150

Hooke, W. H. (1968). lonospheric irregularities produced by internal atmospheric gravity waves. J. Atmos. Terr. Phys., 38(5), 795-823. https://doi.org/10.1016/S0021-9169(68)80033-9

Huang, F. Q., Dou, X. K., Lei, J. H., Lin, J., Ding, F., and Zhong, J. H. (2016). Statistical analysis of nighttime medium-scale traveling ionospheric disturbances using airglow images and GPS observations over central China. J. Geophys. Res., 121(9), 8887-8899. https://doi.org/10.1002/2016JA022760

Hysell, D., Larsen, M., Fritts, D., Laughman, B., and Sulzer, M. (2018). Major upwelling and overturning in the mid-latitude $\mathrm{F}$ region ionosphere. Nat. 
Commun., 9(1), 3326. https://doi.org/10.1038/s41467-018-05809-x

Jiang, C. H., Yang, G. B., Liu, J., and Zhao, Z. Y. (2019). A study of the F2 layer stratification on ionograms using a simple model of TIDs. J. Geophys. Res., 124(2), 1317-1327. https://doi.org/10.1029/2018JA026040

Kagan, L. M., and Kelley, M. C. (1998). A wind-driven gradient drift mechanism for mid-latitude E-region ionospheric irregularities. Geophys. Res. Lett., 25(22), 4141-4144. https://doi.org/10.1029/1998GL900123

Kelley, M. C., Larsen, M. F., LaHoz, C., and McClure, J. P. (1981). Gravity wave initiation of equatorial spread F: A case study. J. Geophys. Res., 86(A11), 9087-9100. https://doi.org/10.1029/JA086iA11p09087

Kelley, M. C., and Fukao, S. (1991). Turbulent upwelling of the mid-latitude ionosphere: 2. Theoretical framework. J. Geophys. Res., 96(A3), 3747-3753. https://doi.org/10.1029/90JA02252

Kelley, M. C., Haldoupis, C., Nicolls, M. J., Makela, J. J., Belehaki, A., Shalimov, S., and Wong, V. K. (2003). Case studies of coupling between the $E$ and $F$ regions during unstable sporadic-E conditions. J. Geophys. Res., 108(A12), 1447. https://doi.org/10.1029/2003JA009955

Kelley, M. C. (2009). The Earth's lonosphere: Plasma Physics and Electrodynamics. San Diego, CA, USA: Academic.

Kotake, N., Otsuka, Y., Tsugawa, T., Ogawa, T., and Saito, A. (2006). Climatological study of GPS total electron content variations caused by medium-scale traveling ionospheric disturbances. J. Geophys. Res., 111(A4), A04306. https://doi.org/10.1029/2005JA011418

Kotake, N., Otsuka, Y., Ogawa, T., Tsugawa, T., and Saito, A. (2007). Statistical study of medium-scale traveling ionospheric disturbances observed with the GPS networks in Southern California. Earth Planets Space, 59(2), 95-102. https://doi.org/10.1186/BF03352681

Larsen, M. F., Fukao, S., Yamamoto, M., Tsunoda, R., Igarashi, K., and Ono, T. (1998). The SEEK chemical release experiment: Observed neutral wind profile in a region of sporadic E. Geophys. Res. Lett., 25(11), 1789-1792. https://doi.org/10.1029/98GL00986

Larsen, M. F. (2000). A shear instability seeding mechanism for quasiperiodic radar echoes. J. Geophys. Res., 105(A11), 24931-24940. https://doi.org/10.1029/1999JA000290

Larsen, M. F., Yamamoto, M., Fukao, S., Tsunoda, R. T., and Saito, A. (2005). Observations of neutral winds, wind shears, and wave structure during a sporadic-E/QP event. Ann. Geophys., 23(7), 2369-2375. https://doi.org/10.5194/angeo-23-2369-2005

Li, G., Ning, B., Hu, L., Liu, L., Yue, X., Wan, W., Zhao, B., Igarashi, K., Kubota, M., ... Liu, J. (2010). Longitudinal development of low-latitude ionospheric irregularities during the geomagnetic storms of July 2004. J. Geophys. Res., 115(A4), A04304. https://doi.org/10.1029/2009ja014830

Li, G. Z., Ning, B. Q., Hu, L. H., and Li, M. (2013). Observations on the field-aligned irregularities using Sanya VHF radar: 2. Low latitude lonospheric E-region quasi-periodic echoes in the East Asian sector. Chin. J. Geophys. (in Chinese), 56(7), 2141-2151. https://doi.org/10.6038/cjg20130701

Li, G. Z., Ning, B. Q., and Hu, L. H. (2014). Interferometry observations of lowlatitude E-region irregularity patches using the Sanya VHF radar. Sci. China Technol. Sci., 57(8), 1552-1561. https://doi.org/10.1007/s11431-014-5592-3

Lindzen, R. S., and Hong, S. S. (1974). Effects of mean winds and horizontal temperature gradients on solar and lunar semidiurnal tides in the atmosphere. J. Atmos. Sci., 31(5), 1421-1466. https://doi.org/10.1175/15200469(1974)031<1421:EOMWAH>2.0.CO;2

Liu, Y., Zhou, C., Tang, Q., Li, Z. Q., Song, Y., Qing, H. Y., Ni, B. B., and Zhao, Z. Y. (2018). The seasonal distribution of sporadic $E$ layers observed from radio occultation measurements and its relation with wind shear measured by TIMED/TIDI. Adv. Space Res., 62(2), 426-439. https://doi.org/10.1016/j.asr.2018.04.026

Liu, Y., Zhou, C., Tang, Q., Kong, J., Gu, X. D., Ni, B. B., Yao, Y. B., and Zhao, Z. Y. (2019). Evidence of mid- and low-latitude nighttime ionospheric $E-F$ coupling: coordinated observations of sporadic $E$ layers, F-region fieldaligned irregularities, and medium-scale traveling ionospheric disturbances. IEEE Trans. Geosci. Remote Sens., 57(10), 7547-7557. https://doi.org/10.1109/TGRS.2019.2914059

Liu, Y., Zhou, C., Xu, T., Wang, Z. K., Tang, Q., Deng, Z. X., and Chen, G. Y. (2020).
Investigation of midlatitude nighttime ionospheric $E-F$ coupling and interhemispheric coupling by using COSMIC GPS radio occultation measurements. J. Geophys. Res., 125(3), e2019JA027625. https://doi.org/10.1029/2019JA027625

MacDougall, J. W. (1974). $110 \mathrm{~km}$ neutral zonal wind patterns. Planet. Space Sci., 22(4), 545-558. https://doi.org/10.1016/0032-0633(74)90089-0

Makela, J. J., and Otsuka, Y. (2011). Overview of nighttime ionospheric instabilities at low- and mid-latitudes: coupling aspects resulting in structuring at the mesoscale. Space Sci. Rev., 168(1-4), 419-440. https://doi.org/10.1007/s11214-011-9816-6

Maksyutin, S. V., and Sherstyukov, O. N. (2005). Dependence of E-sporadic layer response on solar and geomagnetic activity variations from its ion composition. Adv. Space Res., 35(8), 1496-1499. https://doi.org/10.1016/j.asr.2005.05.062

Martinis, C., Baumgardner, J., Wroten, J., and Mendillo, M. (2010). Seasonal dependence of MSTIDs obtained from $630.0 \mathrm{~nm}$ airglow imaging at Arecibo. Geophys. Res. Lett., 37(11), L11103. https://doi.org/10.1029/2010GL043569

Martinis, C., Baumgardner, J., Mendillo, M., Wroten, J., MacDonald, T., Kosch, M. Lazzarin, M., and Umbriaco, G. (2019). First conjugate observations of Medium-Scale Traveling lonospheric Disturbances (MSTIDs) in the EuropeAfrica longitude sector. J. Geophys. Res., 124(3), 2213-2222. https://doi.org/10.1029/2018JA026018

Maruyama, T., Fukao, S., and Yamamoto, M. (2000). A possible mechanism for echo striation generation of radar backscatter from midlatitude sporadic $E$. Radio Sci., 35(5), 1155-1164. https://doi.org/10.1029/1999RS002296

Maruyama, T., Saito, S., Yamamoto, M., and Fukao, S. (2006). Simultaneous observation of sporadic $E$ with a rapid-run ionosonde and VHF coherent backscatter radar. Ann. Geophys., 24(1), 153-162. https://doi.org/10.5194/angeo-24-153-2006

Mathews, J. D. (1998). Sporadic E: Current views and recent progress. J. Atmos. Sol. Terr. Phys., 60(4), 413-435. https://doi.org/10.1016/S13646826(97)00043-6

Mathews, J. D., González, S., Sulzer, M. P., Zhou, Q. H., Urbina, J., Kudeki, E., and Franke, S. (2001). Kilometer-scale layered structures inside spread-F. Geophys. Res. Lett., 28(22), 4167-4170. https://doi.org/10.1029/2001GL013077

Ogawa, T., Takahashi, O., Otsuka, Y., Nozaki, K., Yamamoto, M., and Kita, K. (2002). Simultaneous middle and upper atmosphere radar and ionospheric sounder observations of midlatitude $E$ region irregularities and sporadic $E$ layer. J. Geophys. Res., 107(A10), 1275. https://doi.org/10.1029/2001JA900176

Otsuka, Y., Shiokawa, K., Ogawa, T., and Wilkinson, P. (2004). Geomagnetic conjugate observations of medium-scale traveling ionospheric disturbances at midlatitude using all-sky airglow imagers. Geophys. Res. Lett., 31(15), L15803. https://doi.org/10.1029/2004GL020262

Otsuka, Y., Onoma, F., Shiokawa, K., Ogawa, T., Yamamoto, M., and Fukao, S. (2007). Simultaneous observations of nighttime medium-scale traveling ionospheric disturbances and $\mathrm{E}$ region field-aligned irregularities at midlatitude. J. Geophys. Res., 112(A06317). https://doi.org/10.1029/2005JA011548

Otsuka, Y., Shiokawa, K., Ogawa, T., Yokoyama, T., and Yamamoto, M. (2009). Spatial relationship of nighttime medium-scale traveling ionospheric disturbances and $F$ region field-aligned irregularities observed with two spaced all-sky airglow imagers and the middle and upper atmosphere radar. J. Geophys. Res., 114(A5), A05302. https://doi.org/10.1029/2008JA013902

Otsuka, Y., Suzuki, K., Nakagawa, S., Nishioka, M., Shiokawa, K., and Tsugawa, T. (2013). GPS observations of medium-scale traveling ionospheric disturbances over Europe. Ann. Geophys., 31(2), 163-172. https://doi.org/10.5194/angeo-31-163-2013

Pancheva, D., Haldoupis, C., Meek, C. E., Manson, A. H., and Mitchell, N. J. (2003). Evidence of a role for modulated atmospheric tides in the dependence of sporadic E layers on planetary waves. J. Geophys. Res., 108(A5), 1176. https://doi.org/10.1029/2002JA009788 
Patra, A. K., Venkateswara Rao, N., and Choudhary, R. K. (2009). Daytime lowaltitude quasi-periodic echoes at Gadanki: Understanding of their generation mechanism in the light of their Doppler characteristics. Geophys. Res. Lett., 36(5), L05107. https://doi.org/10.1029/2008GL036670

Paul, K. S., Haralambous, H., Oikonomou, C., and Paul, A. (2019). Long-term aspects of nighttime spread $\mathrm{F}$ over a low mid-latitude European station. Adv. Space Res., 64(6), 1199-1216. https://doi.org/10.1016/j.asr.2019.06.020

Pedatella, N. M., Liu, H. L., Richmond, A. D., Maute, A., and Fang, T. W. (2012). Simulations of solar and lunar tidal variability in the mesosphere and lower thermosphere during sudden stratosphere warmings and their influence on the low-latitude ionosphere. J. Geophys. Res., 117(A8), A08326. https://doi.org/10.1029/2012JA017858

Pietrella, M., and Bianchi, C. (2009). Occurrence of sporadic-E layer over the ionospheric station of Rome: Analysis of data for thirty-two years. Adv. Space Res., 44(1), 72-81. https://doi.org/10.1016/j.asr.2009.03.006

Perkins F. (1973). Spread F and ionospheric currents. J. Geophys. Res., 78(1), 218-226. https://doi.org/10.1029/JA078i001p00218

Ratcliffe, J. A. (1972). An Introduction to the lonosphere and Magnetosphere. Cambridge: Cambridge University Press.

Saito, A., Nishimura, M., Yamamoto, M., Fukao, S., Tsugawa, T., Otsuka, Y., Miyazaki, S., and Kelley, M. C. (2002). Observations of traveling ionospheric disturbances and 3-m scale irregularities in the nighttime F-region ionosphere with the MU radar and a GPS network. Earth Planets Space, 54, 31-44. https://doi.org/10.1186/BF03352419

Schlegel, K., and Haldoupis, C. (1994). Observation of the modified two-stream plasma instability in the midlatitude $E$ region ionosphere. J. Geophys. Res., 99(A4), 6219-6226. https://doi.org/10.1029/93JA02869

Shi, J. K., Wang, G. J., Reinisch, B. W., Shang, S. P., Wang, X., Zherebotsov, G., and Potekhin, A. (2011). Relationship between strong range spread $F$ and ionospheric scintillations observed in Hainan from 2003 to 2007. J. Geophys. Res., 116(A8), A08306. https://doi.org/10.1029/2011JA016806

Shiokawa, K., Ihara, C., Otsuka, Y., and Ogawa, T. (2003). Statistical study of nighttime medium-scale traveling ionospheric disturbances using midlatitude airglow images. J. Geophys. Res., 108(A1), 1052. https://doi.org/10.1029/2002JA009491

Simon, A. (1963). Instability of a partially ionized plasma in crossed electric and magnetic fields. Phys. Fluids, 6(3), 382-388. https://doi.org/10.1063/1.1706743

Smith E. K. (1957). Worldwide occurrence of sporadic E. NBS Circular 582, Washington. D.C: U.S. Gort. Printing Office.

Sripathi, S., Patra, A. K., Sivakumar, V., and Rao, P. B. (2003). Shear instability as a source of the daytime quasi-periodic radar echoes observed by the Gadanki VHF radar. Geophys. Res. Lett., 30(22), 2149. https://doi.org/10.1029/2003GL017544

Stening, R. J., Forbes, J. M., Hagan, M. E., and Richmond, A. D. (1997). Experiments with a lunar atmospheric tidal model. J. Geophys. Res., 102(D12), 13465-13471. https://doi.org/10.1029/97JD00778

Sun, L., Xu, J., Wang, W., Yue, X., Yuan, W., Ning, B., Zhang, D., and de Meneses, F. C. (2015). Mesoscale field-aligned irregularity structures (FAls) of airglow associated with medium-scale traveling ionospheric disturbances (MSTIDs). J. Geophys. Res., 120(11), 9839-9858. https://doi.org/10.1002/2014JA020944

Swartz, W. E., Kelley, M. C., Makela, J. J., Collins, S. C., Kudeki, E., Franke, S., Urbina, J., Aponte, N., Sulzer, M. P., and González, S. A. (2000). Coherent and incoherent scatter radar observations during intense mid-latitude spread $\mathrm{F}$. Geophys. Res. Lett., 27(18), 2829-2832. https://doi.org/10.1029/2000GL000021

Tang, Q., Zhou, C., Liu, Y., and Chen, G. Y. (2020). Response of sporadic $E$ layer to sudden stratospheric warming events observed at low and middle latitudes. J. Geophys. Res., 125(2), e2019JA027283. https://doi.org/10.1029/2019JA027283

Tsunoda, R. T., Fukao, S., and Yamamoto, M. (1994). On the origin of quasiperiodic radar backscatter from midlatitude sporadic E. Radio Sci., 29(1), 349-365. https://doi.org/10.1029/93RS01511

Tsunoda, R. T., and Cosgrove, R. B. (2001). Coupled electrodynamics in the nighttime midlatitude ionosphere. Geophys. Res. Lett., 28(22), 4171-4174. https://doi.org/10.1029/2001GL013245
Tsunoda, R. T., Cosgrove, R. B., and Ogawa, T. (2004). Azimuth-dependent $E_{s}$ layer instability: A missing link found. J. Geophys. Res., 109(A12), A12303. https://doi.org/10.1029/2004JA010597

Vadas, S. L. (2007). Horizontal and vertical propagation and dissipation of gravity waves in the thermosphere from lower atmospheric and thermospheric sources. J. Geophys. Res., 112(A6), A06305. https://doi.org/10.1029/2006JA011845

Valladares, C. E., and Sheehan, R. (2016). Observations of conjugate MSTIDs using networks of GPS receivers in the American sector. Radio Sci., 51(9), 1470-1488. https://doi.org/10.1002/2016RS005967

Venkateswara Rao, N., Patra, A. K., and Rao, S. V. B. (2008). Some new aspects of low-latitude E-region QP echoes revealed by Gadanki radar: Are they due to Kelvin-Helmholtz instability or gravity waves?. J. Geophys. Res., 113(A3), A03309. https://doi.org/10.1029/2007JA012574

Wang, G. J., Shi, J. K., Wang, X., Shang, S. P., Zherebtsov, G., and Pirog, O. M. (2010). The statistical properties of spread $F$ observed at Hainan station during the declining period of the 23rd solar cycle. Ann. Geophys., 28(6), 1263-1271. https://doi.org/10.5194/angeo-28-1263-2010

Wang, N., Guo, L. X., Zhao, Z. W., Ding, Z. H., and Lin, L. K. (2018). Spread-F occurrences and relationships with foF 2 and $h^{\prime} F$ at low- and mid-latitudes in China. Earth Planets Space, 70(1), 59. https://doi.org/10.1186/s40623-0180821-9

Whitehead, J. D. (1960). The formation of the Sporadic-E layer in the temperate zones. J. Atmos. Terr. Phys., 20(1), 49-58. https://doi.org/10.1016/00219169(61)90097-6

Wilkinson, P. J., Szuszczewicz, E. P., and Roble, R. G. (1992). Measurements and modelling of intermediate, descending, and sporadic layers in the lower ionosphere: results and implications for global-scale ionosphericthermospheric studies. Geophys. Res. Lett., 19(2), 95-98. https://doi.org/10.1029/91GL02774

Woodman, R. F., Yamamoto, M., and Fukao, S. (1991). Gravity wave modulation of gradient drift instabilities in mid-latitude sporadic $E$ irregularities. Geophys. Res. Lett., 18(7), 1197-1200. https://doi.org/10.1029/91GL01159

Xiao, S. G., Shi, J. K., Zhang, D. H., Hao, Y. Q., and Huang, W. Q. (2012). Observational study of daytime ionospheric irregularities associated with typhoon. Sci. China Tech. Sci., 55(5), 1302-1304. https://doi.org/10.1007/s11431-012-4816-7

Yamamoto, M., Fukao, S., Woodman, R. F., Ogawa, T., Tsuda, T., and Kato, S. (1991). Mid-latitude $E$ region field-aligned irregularities observed with the MU radar. J. Geophys. Res., 96(A9), 15943-15949. https://doi.org/10.1029/91JA01321

Yamamoto, M., Fukao, S., Ogawa, T., Tsuda, T., and Kato, S. (1992). A morphological study on mid-latitude $E$-region field-aligned irregularities observed with the MU radar. J. Atmos. Terr. Phys., 54(6), 769-777. https://doi.org/10.1016/0021-9169(92)90115-2

Yamamoto, M., Komoda, N., Fukao, S., Tsunoda, R. T., Ogawa, T., and Tsuda, T. (1994). Spatial structure of the $E$ region field-aligned irregularities revealed by the MU radar. Radio Sci., 29(1), 337-347. https://doi.org/10.1029/93RS01846

Yokoyama T., Yamamoto M., and Fukao S. (2003). Computer simulation of polarization electric fields as a source of mid-latitude field-aligned irregularities. J. Geophys. Res., 108(A2), 1054. https://doi.org/10.1029/2002JA009513

Yokoyama, T., Yamamoto, M., Fukao, S., and Cosgrove, R. B. (2004a). Threedimensional simulation on generation of polarization electric field in the midlatitude E-region ionosphere. J. Geophys. Res., 109(A1), A01309. https://doi.org/10.1029/2003JA010238

Yokoyama, T., Horinouchi, T., Yamamoto, M., and Fukao, S. (2004b). Modulation of the midlatitude ionospheric $\mathrm{E}$ region by atmospheric gravity waves through polarization electric field. J. Geophys. Res., 109(A12), A12307. https://doi.org/10.1029/2004JA010508

Yokoyama, T., Otsuka, Y., Ogawa, T., Yamamoto, M., and Hysell, D. L. (2008). First three-dimensional simulation of the Perkins instability in the nighttime midlatitude ionosphere. Geophys. Res. Lett., 35(3), L03101. https://doi.org/10.1029/2007GL032496

Yokoyama, T., Hysell, D. L., Otsuka, Y., and Yamamoto, M. (2009). Three- 
dimensional simulation of the coupled Perkins and $E_{s}$-layer instabilities in the nighttime midlatitude ionosphere. J. Geophys. Res., 114(A3), A03308. https://doi.org/10.1029/2008JA013789

Yokoyama, T. (2014). Hemisphere-coupled modeling of nighttime mediumscale traveling ionospheric disturbances. Adv. Space Res., 54(3), 481-488. https://doi.org/10.1016/j.asr.2013.07.048

Zhang, Y. B., Wu, J., Guo, L. X., Hu, Y. L., Zhao, H. S., and Xu, T. (2015). Influence of solar and geomagnetic activity on sporadic-E layer over low, mid and high latitude stations. Adv. Space Res., 55(5), 1366-1371. https://doi.org/10.1016/j.asr.2014.12.010

Zhou, C., Tang, Q., Song, X. X., Qing, H. Y., Liu, Y., Wang, X., Gu, X. D., Ni, B. B., and Zhao, Z. Y. (2017). A statistical analysis of sporadic $E$ layer occurrence in the midlatitude China region. J. Geophys. Res., 122(3), 3617-3631. https://doi.org/10.1002/2016JA023135

Zhou, C., Liu, Y., Tang, Q., Gu, X. D., Ni, B. B., and Zhao, Z. Y. (2018a). Investigation on the occurrence of mid-latitude E-region irregularity by Wuhan VHF radar and its relationship with sporadic E layer. IEEE Trans. Geosci. Remote Sens., 56(12), 7207-7216. https://doi.org/10.1109/TGRS.2018.2849359

Zhou, C., Tang, Q., Huang, F. Q., Liu, Y., Gu, X. D., Lei, J. H., Ni, B. B., and Zhao, Z. Y. (2018b). The simultaneous observations of nighttime ionospheric $E$ region irregularities and $F$ region medium-scale traveling ionospheric disturbances in midlatitude China. J. Geophys. Res., 123(6), 5195-5209. https://doi.org/10.1029/2018JA025352 